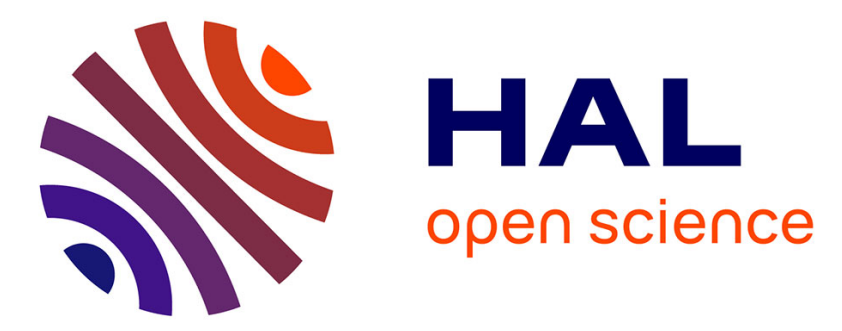

\title{
Experimental study of Built-Up Layer formation during machining of High Strength free cutting steel
}

Jean-Edouard Desaigues, Christophe Lescalier, Anne Bomont-Arzur, Daniel Dudzinski, Olivier Bomont

\section{- To cite this version:}

Jean-Edouard Desaigues, Christophe Lescalier, Anne Bomont-Arzur, Daniel Dudzinski, Olivier Bomont. Experimental study of Built-Up Layer formation during machining of High Strength free cutting steel. Journal of Materials Processing Technology, 2016, 236, pp.204-215. 10.1016/j.jmatprotec.2016.05.016 . hal-01367004

\section{HAL Id: hal-01367004 https://hal.science/hal-01367004}

Submitted on 15 Sep 2016

HAL is a multi-disciplinary open access archive for the deposit and dissemination of scientific research documents, whether they are published or not. The documents may come from teaching and research institutions in France or abroad, or from public or private research centers.
L'archive ouverte pluridisciplinaire HAL, est destinée au dépôt et à la diffusion de documents scientifiques de niveau recherche, publiés ou non, émanant des établissements d'enseignement et de recherche français ou étrangers, des laboratoires publics ou privés. 


\title{
EXPERIMENTAL STUDY OF BUILT-UP LAYER FORMATION DURING MACHINING OF HIGH STRENGTH FREE-CUTTING STEEL
}

\author{
Jean-Edouard Desaigues ${ }^{1}$, Christophe Lescalier ${ }^{2}$, Anne Bomont-Arzur ${ }^{1}$, \\ Daniel Dudzinski $i^{3}$, Olivier Bomont ${ }^{2}$ \\ (1) ArcelorMittal Global R\&D Long Carbon - Gandrange R\&D Centre - Rue des Serruriers \\ - 57175 Gandrange - France \\ (2) Arts et Métiers ParisTech - LEM3 - UMR CNRS 7239 - 4 rue Augustin Fresnel - 57070 \\ Metz - France \\ (3) Université de Lorraine - LEM3 - UMR CNRS 7239 - 4 rue Augustin Fresnel - 57070 \\ Metz - France
}

\begin{abstract}
Machinability of high-strength steels can be improved without degrading the mechanical properties using metallurgical solutions to create or retain non-metallic inclusions. Such a metallurgical treatment usually leads, during machining, to the appearance of so-called Built-Up Layers (BULs) or transfer layers on the cutting tool. These BULs protect the tool against wear, and longer tool life or better productivity is achieved. Formation of such BULs on the cutting tool depends on many parameters i.e. tool geometry, tool material, cutting conditions. This paper proposes an experimental methodology to identify and describe BUL occurring on the tool rake face. Machining tests were carried out with a high strength free-cutting steel using an untested AISiTiN coated carbide tool. BULs morphology and composition were determined for various cutting conditions. Temperature distributions at the tool-chip interface were measured during the cutting tests using an infrared camera. BUL appearance was then linked to the thermo-mechanical conditions at the tool-chip interface.
\end{abstract}

Keywords: Machinability, High Strength Steels, Built-Up Layer, Inclusions, IR thermography 


\section{Introduction}

Machining often accounts for a substantial percentage of the cost of mechanical parts and up to $65 \%$ for automotive steel parts (Kirsch-Racine et al., 2007). This is why machinability is thoroughly investigated by steelmakers. Machinability is currently defined as the ability of a material to be formed by cutting processes. It is usually assessed through four main parameters: cutting forces, tool life, surface finish and chip control (Chandrasekaran, 1988) or (Klocke, 2001). Steelmakers have specifically developed steels with high machinability: the free-cutting steels which allow reaching high removal rates as well as longer tool lives. They are mainly low carbon steels with high sulphur contents but unfortunately poor mechanical performances. Downsizing is a current trend in mechanical industry especially in automotive industry and requires steel grades with higher mechanical performances and acceptable machinability. This is the reason why high strength free-cutting steels are developed.

Steel machinability depends on steel composition, microstructure and inclusions (Stahl, 2012). Composition and microstructure are defined according to mechanical properties specifications. The most relevant way to enhance machinability is to custom metallic and non-metallic inclusions. Two main solutions are currently used: increase sulphur content and/or promote some oxide types. However high sulphur content decreases some steel properties such as notch toughness or fatigue resistance and makes forging operations more difficult. This is why steelmakers also focus on oxide inclusions trying to produce ductile oxide types with low abrasiveness.

In a first part, this paper presents a brief review about steel inclusions influence on machinability, and it focuses especially on the formation of Built-Up Layers (BUL) which are well-known to enhance the chip flow at the tool-chip interface and to reduce the tool wear. In a second part, an experimental approach of machinability is performed on high strength free-cutting steel highlighting the benefits of inclusions. The high MnS (Manganese Sulphide) content of this steel is assumed to bring a very good chip breakage, and combined with the oxides, the non-metallic inclusions may contribute to the formation of Built-Up Layers. The main objective of this study was thus to investigate the conditions of BUL appearance and its effect on cutting forces, temperatures and more generally on steel machinability.

\section{Influence of inclusions on steel machinability}

Kiessling proposes an important work (Kiessling and Lange, 1990) about steel inclusions and discusses the influence of non-metallic inclusions on steel machinability. He gives an interesting review of the early works. He also refers to the excellent summary of metallurgical aspects of cutting given by Trent and Wright now gathered in (Trent and Wright, 2000).

The inclusions affect all the factors defining the machinability, i.e. tool life, surface quality, cutting force level, and chip formation. In an elementary cutting process, the chip is formed by intense shearing in the primary shear zone, PSZ; a secondary shear zone SSZ appears along the tool-chip interface, also called flow zone. In this zone the chip adheres to the tool rake face (seized region) and then slides (sliding region) and finally breaks contact with tool. The flow zone plays an important role in the cutting process; plastic deformations, stresses and temperatures are there pretty high. Non-metallic inclusions affect the shear process in both primary shear zone and flow zone. In the PSZ, inclusions act as 
stress-raisers initiating crack formation and then embrittling the chip (Bernsmann et al., 2001). In the flow zone, inclusions are also strongly bonded to the rake face and plastically deformed in the chip flow direction. They also act there as stress raisers and may form a thin layer i.e. a Built-Up Layer which mainly protects the tool rake face and increases tool life. The overall influence of inclusions on machinability depends on their quantity, size, shape, distribution, physical and mechanical properties (Gladman and Pickering, 1962). In the following, effects of sulphides and oxides inclusions are described first then the formation of a Built-Up Layer is detailed.

\subsection{Sulphides inclusions}

Sulphur is the most important non-metallic element present in the composition of free-cutting steel. The main part of sulphur is combined with manganese, forming manganese sulphide inclusions. According to Kiessling and Lange (1990), the other main sulphide inclusions types are iron sulphide FeS and (Mn,Me)S (Me as metal). The first detailed studies on the positive effect of sulphides on steel machinability were performed during the sixties and were continued in the following decades until today.

In their study, Naylor et al. (1976) observed that an increase in sulphur content results in shorter chips; and Trent and Wright (2000) noted that this reduces the tool-chip contact length and decreases cutting forces. Unfortunately it affects mechanical properties such as notch toughness.

Three different types of manganese sulphide inclusions are to be distinguished according to Sims and Dahle (1938), each having its particular shape and characteristics:

- Type 1 sulphides are spheroidal due to their solidification in the liquid metal. They are found regularly distributed in steel. The melting point of pure $\mathrm{MnS}$ is about $1600^{\circ} \mathrm{C}$. Sulphides in steel are not pure and contain oxides $\left(\mathrm{FeO}, \mathrm{MnO}, \mathrm{SiO}_{2}\right)$ and $\mathrm{FeS}$ which decrease the melting temperature under the liquidus of steel (around $1500^{\circ} \mathrm{C}$ ).

- Type 2 sulphides were first observed on final products having concentrations of about 0.002 \%wt. Al and about $0.008 \%$ wt. active oxygen. These sulphides are usually found in killed steel when a too strong deoxidization leads to a too low level of oxygen (lower than $0.01 \%$ ). They segregate in a eutectic like MnS-phase at $1180^{\circ} \mathrm{C}$. Type 2 sulphides are not supposed to be found in closed segments but rather as fine sulphides in a fan or chain like pattern, actually precipitated as interconnected branched rods. These sulphide inclusions can be considered as detrimental to the machinability.

- Type 3 sulphides appear at very low oxygen contents in iron melts with low melting temperature. They are randomly dispersed. Their shape is angular or faceted. These sulphides only occur when an excessive amount of deoxidizer is used; this should be avoided by the steelmaker. This type of sulphide should not be found in steel.

The most common solution adopted by steelmakers consists in limiting the sulphur content and promoting type 1 sulphides which are softer and less abrasive than types 2 and 3 . During the cutting process, sulphide inclusions are elongated in the primary shear zone, and more extensively in the flow zone adjacent to the tool-chip interface where additional shearing occurs. As noted by (Kiessling and Lange, 1990), sulphide inclusions act as stress raisers in the shear zones and then facilitate chip 
formation and chip flow. This stress raising effect depends on inclusions shape and size. At the toolchip interface low concentration of elongated sulphide inclusions is more efficient than a high concentration of small spheroid inclusions. Gladman and Pickering (1962) compared the friction force at the tool-chip interface and the number of sulphide inclusions. Machinability is improved by an increasing size of sulphide particles and a decreasing number.

Finally, it was experimentally verified that sulphide inclusions can be continuously deposited on rake and flank faces of the tool and deformed to form thin layers. These thin layers act as diffusion protective barriers (Bittes, 1993). The formation of these transfer or Built-Up Layers is examined in the following.

\subsection{Oxides inclusions}

Steelmaking processes produce oxide inclusions: endogenous inclusions provided by steel deoxidation and exogenous inclusions due to slag or refractories. Oxide inclusions fall into two main categories: hard and brittle inclusions on the one hand and malleable ones on the other. Hard and brittle inclusions never deform plastically at any temperature encountered in steel cutting process and have thus a detrimental effect on steel machinability. They are often sharp-edged and induce a high tool wear rate. Corundum, escolaite or spinels belong to this category (Kiessling and Lange, 1990). Some other oxide inclusions can deform plastically in the primary and/or the secondary shear zone and are gathered in the second category. Inclusions within particular composition ranges in the $\mathrm{MnO}-\mathrm{SiO}_{2}-$ $\mathrm{Al}_{2} \mathrm{O}_{3}$ and $\mathrm{CaO}-\mathrm{SiO}_{2}-\mathrm{Al}_{2} \mathrm{O}_{3}$ systems belong to this category. Specific metallurgical treatments such as calcium treatment have been developed to preferentially form these types of oxide inclusion phases. Kiessling and Lange describe their effects on Al and Si-deoxidized steels (Kiessling and Lange, 1990). After Ca-treatment, manganese sulphide inclusions composition can be also modified leading to less malleable inclusions. Aluminium oxides are transformed to complex $\mathrm{CaO}-\mathrm{Al}_{2} \mathrm{O}_{3}$ or $\mathrm{CaO}-\mathrm{Al}_{2} \mathrm{O}_{3}-\mathrm{SiO}_{2}$, depending on the initial deoxidation process. The new complex oxides have a smoother geometry reducing their abrasiveness. Silicates are also transformed into complex $\mathrm{CaO}-\mathrm{Al}_{2} \mathrm{O}_{3}-\mathrm{SiO}_{2}$ inclusions. When sulphur content is high, calcium treatment can modify the sharp-edged $\mathrm{Al}_{2} \mathrm{O}_{3}$ inclusions into globular calcium-aluminates surrounded by soft rims of (Ca,Mn)S (Ruppi et al., 1998). During cutting of Ca-treated steels, adhering layers with compositions similar to that of the inclusions in steel are often formed on the tool. These Built-Up Layers reduce tool wear, especially crater wear (Larsson and Ruppi, 2001).

As for the sulphide inclusions, the oxide inclusions which deform plastically have a positive influence in the shear zones of the cutting process. Chip breakage is favoured. The inclusions layers or Built-Up Layers formed on the tool faces have a lubrication effect limiting the increase in temperature at the tool-chip and tool-work material interfaces (Bittes, 1993) and act as diffusion protective barriers.

\subsection{Built-Up Layer}

Built-Up Edge BUE and Built-Up Layer BUL are two different phenomena. BUE corresponds to the accumulation of work material greatly strengthened by extremely severe strain adhering around the cutting edge (Trent and Wright, 2000); it occurs at low cutting speeds. BUL corresponds to a selective 
transfer layer (Hamann et al., 1994); it appears when inclusions, mainly sulphide and/or oxide inclusions, are transferred from the work material onto the rake face (or the flank face) as a thin layer. Thus, two points differentiate these two phenomena: the morphology and the composition.

BULs are observed when machining several kinds of steels: leaded and unleaded low carbon freecutting steels (Essel, 2006), low alloy medium carbon steels with various sulphur contents and calcium treatment (Bittes, 1993), calcium treated stainless steels (M'Saoubi and Chandrasekaran, 2005)

BULs are detected on the rake face and the flank face of the tool, as reported by (Essel, 2006) or (Nordgren and Melander, 1990). On the rake face, the BUL is deposited in the chip flow direction and is located in the central region of the tool-chip interface (Qi and Mills, 2000). As noted by these authors, BUL formation, as all the phenomena occurring in the flow zone (secondary shear zone), depends on the local conditions of stress, shear, shear rate and temperature, and on the local properties of tool and workpiece. More generally, following Brion (1993), three major parameters control BUL formation: 1 - the inclusionary state of the steel, 2 - the chemical and geometrical nature of the tool surface and 3 - the cutting conditions (cutting speed, feed per revolution, depth of cut). BUL is mainly characterised by its composition, its morphology and its thickness.

For engineering steels with low sulphur, built-up-layers can be composed of sulphide and / or oxide inclusions (Bittes, 1993); and free-cutting steels with high sulphur, BULs mainly contain manganese sulphide MnS, (Brion, 1993).

Tool coating as well as tool material have a major influence on BUL occurrence. Katayama and Imai (1990) machined free cutting steel with uncoated and coated HSS tools. No BUL appeared on uncoated HSS tools. Some coatings promoted BUL formation; they were ranked according to their ability to cover the tool-chip interface with sulphide. The most efficient was $\mathrm{ZrO}_{2}$ coating followed by $\mathrm{TiN}, \mathrm{Al}_{2} \mathrm{O}_{3}$ and TiC coatings. Brion (1993) performed similar experiments with carbide tools and then higher cutting speeds. Ti(C,N) appeared the most efficient coating to create BUL at high cutting speed when machining free-cutting steels. Ruppi et al. obtained similar results; they used coated carbide tools (Ruppi et al., 1998) for their cutting tests on engineering steels. The wear in the sliding zone was reduced with all coatings except for $\mathrm{Al}_{2} \mathrm{O}_{3}$. The decrease in crater wear rates with $\mathrm{TiC}, \mathrm{Ti}(\mathrm{C}, \mathrm{N})$ and $\mathrm{TiN}$ coatings was clearly explained as a result of Ca-treatment. Wicher and Pape (1967) machined low sulphur engineering steels and observed that BUL thickness increases with TiC content in the tool material. Bittes (1993) investigated both low sulphur and resulphurized engineering steels. Cutting tests were performed with a P30 uncoated carbide containing about $8 \%$ TiC. Uncoated carbide tool appeared also able to form sulphide BUL even for low sulphur steels.

According to various authors, such as Brion who has machined free cutting steels with coated and uncoated carbide tools (Brion, 1993) or Helle who has focused on engineering steels machined with carbide tools (Helle, 1995) or Brandt and Mikus who have used ceramic tools to machine engineering steels (Brandt and Mikus, 1987), the BUL can and even should chemically react with the cutting tool during machining. The extremely severe thermo-mechanical conditions occurring at the tool-chip interface could therefore be considered as catalyser, enhancing the possible chemical reactions. It was suggested that chemical reactions, i.e. tool oxidation, can occur to create an efficient and stable BUL. 
Similar trends were found for sulphide and oxide inclusions. A very thin layer composed of oxides such as $\mathrm{CaTiO}_{3}$ could then appear at the tool interfaces. It should promote the adherence of inclusions with which chemical affinity is high. TiC is often identified as a tool substrate component furthering BUL since it reacts with steel oxide inclusions such as $\mathrm{MnO}, \mathrm{SiO}_{2}, \mathrm{FeO}$ and $\mathrm{CaO}+\mathrm{MnS}$ (Helistö et al., 1990). It was also assumed that wettability of non-metallic inclusions with tool is considered as a prerequisite for the BUL formation (Katayama and Hashimura, 1993).

Most of experimental studies on BUL formation were performed using cutting tools with plane rake face even for recent works. Only a few authors led experiments using cutting inserts with chip breaker, for instance Essel (2006) for free cutting steels and Nordgren and Melander (1990) for engineering steels. Chip breaker largely modifies stress distribution at the tool-chip interface (Wang and Jawahir, 2007), and thus BUL location is changed. Sulphide layers were observed in the vicinity of the cutting edge and at the end of the tool-chip contact zone (Nordgren and Melander, 1990) or (Essel, 2006) when BUL is currently observed in the middle of the tool-chip interface with plane rake face.

Many studies highlighted that BUL thickness and even its composition evolve with cutting speed; in particular BUL starts to appear when BUE disappears. Opitz and König (1962) as well as Wicher and Pape (1967) have shown that sulphide inclusions may induce a first Built-Up Layer at low cutting speed since oxides inclusions are involved in BUL at higher cutting speed. Researchers have observed that BUL thickness increases and then reaches a maximum value, up to $30 \mu \mathrm{m}$ for Helle (1995), and progressively decreases leading to a rapid tool wear. This trend has been found for freecutting steels (Brion, 1993), engineering steels (Nordgren and Melander, 1990) and even stainless steels (M'Saoubi and Chandrasekaran, 2005).

In the following, an experimental approach is proposed to study the Built-Up-Layer formation when machining a high strength free-cutting steel. Several metallurgical treatments have been performed on this steel to promote the transfer of non-metallic inclusions onto the tool face and as a consequence enhance its machinability. Tool coating is AISiTiN: its compatibility with BUL formation has not yet been tested. It is devoted to high speed turning when TiN starts to oxidize. Cutting forces and temperatures were measured during the experiments, for various values of cutting speed. The thickness and the chemical composition of BUL were analysed for different cutting times and cutting speeds.

\section{Experimental procedure}

\subsection{Work material}

The investigated steel is a high strength free-cutting steel Usimax ${ }^{\circledR}$ D950 ${ }^{1}$; Table 1 gives an indicative chemical composition, and Table 2 provides its main mechanical properties. Several metallurgical treatments were applied to this steel to enhance both strength and machinability.

\footnotetext{
${ }^{1}$ Usimax is registered trademark of ArcelorMittal Revigny
} 
Table 1

Chemical indicative composition of the Usimax® D950. (wt\%).

\begin{tabular}{ccccccccc}
\hline $\mathrm{C}$ & $\mathrm{Mn}$ & $\mathrm{P}$ & $\mathrm{S}$ & $\mathrm{Si}$ & $\mathrm{Ni}$ & $\mathrm{Cr}$ & $\mathrm{Mo}$ & $\mathrm{Cu}$ \\
$(\%)$ & $(\%)$ & $(\%)$ & $(\%)$ & $(\%)$ & $(\%)$ & $(\%)$ & $(\%)$ & $(\%)$ \\
\hline 0.455 & 1.517 & 0.012 & 0.299 & 0.225 & 0.088 & 0.119 & 0.011 & 0.128 \\
\hline
\end{tabular}

Table 2

Mechanical properties of the Usimax® D950.

\begin{tabular}{ccccc}
\hline $\begin{array}{c}\mathrm{Rp}_{0.2} \\
(\mathrm{MPa})\end{array}$ & $\begin{array}{c}\mathrm{Rm} \\
(\mathrm{MPa})\end{array}$ & $\mathrm{A} \%$ & $\mathrm{Z} \%$ & $\begin{array}{c}\text { Hardness } \\
(\mathrm{HV} 0.5)\end{array}$ \\
\hline 605 & 899 & 14.3 & 23.5 & 288 \\
\hline
\end{tabular}

Oxides composition was modified to avoid hard and sharp-edged alumina oxides which are assumed to be detrimental for machinability. Formation of complex calcio-aluminate oxides, sometimes surrounded by manganese sulphides was favoured. EDX measurements have shown that the average composition of oxides was about $40-45 \% \mathrm{SiO}_{2}, 10-15 \% \mathrm{Al}_{2} \mathrm{O}_{3}, 10-25 \% \mathrm{CaO}$ and $10-20 \% \mathrm{MnO}$. The obtained steel presents a high MnS content which is assumed to bring a very good chip breakage; and combined with malleable oxides the steel appears able to form Built-Up Layers. As an example, Fig. 1 presents an example of a longitudinal view of a hot-rolled bar of the steel showing the MnS inclusions size, shape and distribution.

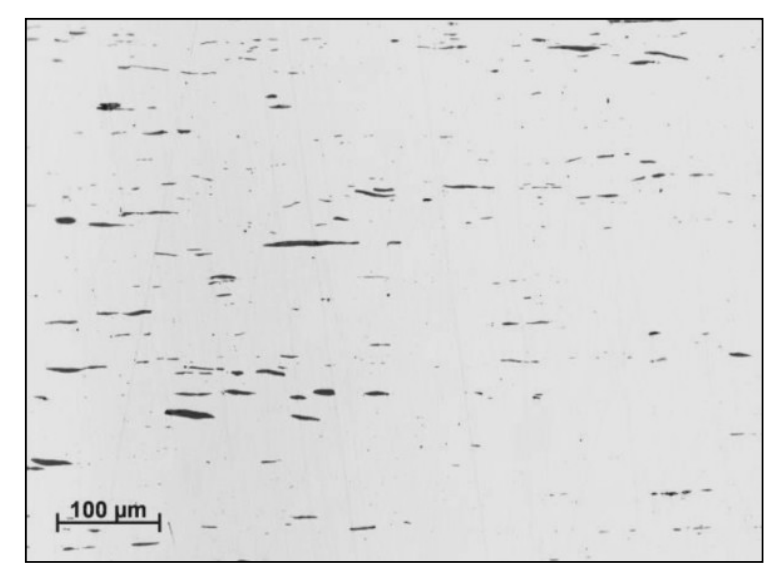

Fig. 1. Distribution of MnS inclusions observed in the cross section of the steel bar.

\subsection{Cutting tool}

Two types of machining tests were performed: bar turning tests for BUL formation observations and orthogonal cutting tests to access cutting temperatures. The tool inserts were, for the two series of tests, KENNAMETAL TPGN 160304 KCU10 (ISO P10) coated carbide inserts. KCU10 grade additionally featured a dual-layer coating application, a top layer of AISiTiN covering a second layer of AITiN. The used tool holders led to a major cutting edge angle $\kappa_{R}$ of $90^{\circ}$ and a major cutting edge inclination angle 
$\lambda_{S}$ of $0^{\circ}$ for both bar turning and orthogonal cutting operations. Cutting insert geometry was positive with a rake angle $\gamma$ and relief angle $\alpha$ respectively equal to $6^{\circ}$ and $5^{\circ}$. Nose radius $r_{\varepsilon}$ was low: $0.4 \mathrm{~mm}$.

\subsection{Machining experiments}

- Bar turning tests

Bar turning tests were performed dry using a SOMAB Optimab $450 \mathrm{CNC}$ lathe. Cutting forces were measured using a 3-components KISTLER 9121 dynamometer. These experiments were carried out to study the influence of cutting speed $V_{C}$ and Uncut Chip Length UCL on the BUL formation on the tool rake face. Four different cutting speeds and five different Uncut Chip Lengths were selected (see Table 3). All the combinations have been tested, leading to 20 cutting tests. For each set of cutting conditions, a new cutting insert was used.

\section{Table 3}

Turning tests conditions.

\begin{tabular}{cccc}
\hline $\mathrm{V}_{\mathrm{C}}(\mathrm{m} / \mathrm{min})$ & $\mathrm{UCL}(\mathrm{m})$ & $\mathrm{ap}_{\mathrm{P}}(\mathrm{mm})$ & $\mathrm{f}(\mathrm{mm} / \mathrm{rev})$ \\
\hline$\{100,200,300,400\}$ & $\{1,3,10,30,200\}$ & 3 & 0.3 \\
\hline
\end{tabular}

Preliminary cutting tests have highlighted feed and depth of cut ranges which promote short and steady chips. Depth of cut was finally chosen ten times greater than the nose radius to minimize the tool nose effect and then provide semi-orthogonal cutting conditions. The high sulphur content of Usimax® steel (about $0.3 \%$ ) implied the rapid onset of BUL formation; therefore only low Uncut Chip Lengths were machined.

After each cutting test, the cutting insert was observed using two techniques:

- Micro topography analysis, using an ALICONA InfiniteFocus SL, in order to describe the BUL morphology (location, covered area, volume, average thickness).

- SEM + EDX analysis, in order to determine the location and composition of the BUL on the tool rake face as well as the tool-chip contact length. Measurements were performed using a JEOL 7001 FLV SEM equipped with an OXFORD EDX probe (Silicon Drive Detector X-Max, $50 \mathrm{~mm}^{2}$ ). EDX analyses were made using an accelerating voltage of $15 \mathrm{kV}$, a working distance of $13 \mathrm{~mm}$. The accelerating voltage was chosen to investigate the upper layers of the BUL. The magnification was $75 \mathrm{x}$. This value was supposed to warrant a broad field of view and a negligible image distortion.

\section{- Orthogonal cutting experiments and IR thermography}

Orthogonal cutting tests were performed dry using a SOMAB Univer 700 milling machine. Cutting forces were measured using a KISTLER 9257A dynamometer. Cutting temperatures were measured using a FLIR SC7600 MWIR camera equipped with a G1 lens. These experiments were devoted to temperature measurement at the tool-chip interface. Cutting conditions are the same as those used for bar turning tests. However cutting depth was reduced to $2 \mathrm{~mm}$ and Uncut Chip Length was limited to 8 meters. 


\section{Table 4}

Orthogonal cutting tests conditions.

\begin{tabular}{cccc}
\hline$V_{C}(\mathrm{~m} / \mathrm{min})$ & $\mathrm{UCL}(\mathrm{m})$ & $\mathrm{a}_{\mathrm{p}}(\mathrm{mm})$ & $\mathrm{f}(\mathrm{mm} / \mathrm{rev})$ \\
\hline$\{100,200,300,400\}$ & 8 & 2 & 0.3 \\
\hline
\end{tabular}

Combined cutting forces and IR thermography measurements were performed in order to describe the thermo-mechanical conditions at the tool-chip interface during the BUL formation. All the cutting tests were performed at least twice, in order to check the reproducibility of the experiments.

\subsection{Experimental setup for the orthogonal tests - IR camera}

The experimental setup devoted to IR measurements has been developed in our laboratory and described in a previous paper (Artozoul et al., 2014).

Experimental samples were tubular parts with an outer diameter of $40 \mathrm{~mm}$. The samples were integrated into the tool holder of the milling machine spindle. Orthogonal cutting conditions were obtained by removing the end of the tubular part of the samples using the cutting tool. This tool was attached to the dynamometric table, which was fixed on the machine table (see Fig. 2. ).

A lateral view of the cutting process (in a plane perpendicular to the cutting edge) was recorded with an infrared camera. This camera was adapted into CNC machine by using a special device screwed onto the machine table. In order to obtain thermal maps of the cutting tool, the chip and to observe the tool-chip interface, the tool insert was ground in a plane perpendicular to the cutting edge. With this experimental setup, both forces and temperature fields were measured simultaneously.

The IR camera used in the experiments was a FLIR SC7600 MWIR equipped with a G1 lens. The spectral range of the complete infrared device extends from 3.5 to $5 \mu \mathrm{m}$. Two temperature ranges were used: the first one up to $300^{\circ} \mathrm{C}$ and the second one from $300^{\circ} \mathrm{C}$ to $1000^{\circ} \mathrm{C}$ (both temperature ranges are given for a black body). Different integration times were employed: from 60 up to $450 \mu$ s depending on the temperature range. The array definition was $432 \times 332$ pixels and the spatial resolution was $15 \mu \mathrm{m}$ x $15 \mu \mathrm{m} /$ pixel, providing a field of view of about $6.48 \mathrm{~mm} \times 4.98 \mathrm{~mm}$. The full frame rate of the camera was about $100 \mathrm{~Hz}$. The chosen settings have enabled an increase in the frame rate which was about $200 \mathrm{~Hz}$. The focal distance was very short (i.e. $30 \mathrm{~mm}$ ) thereby the camera was placed very close to the observed cutting zone (see Fig. 2. ). The Noise Equivalent Temperature Difference (NETD) was less than $25 \mathrm{mK}$ for a black body at $25^{\circ} \mathrm{C}$. 


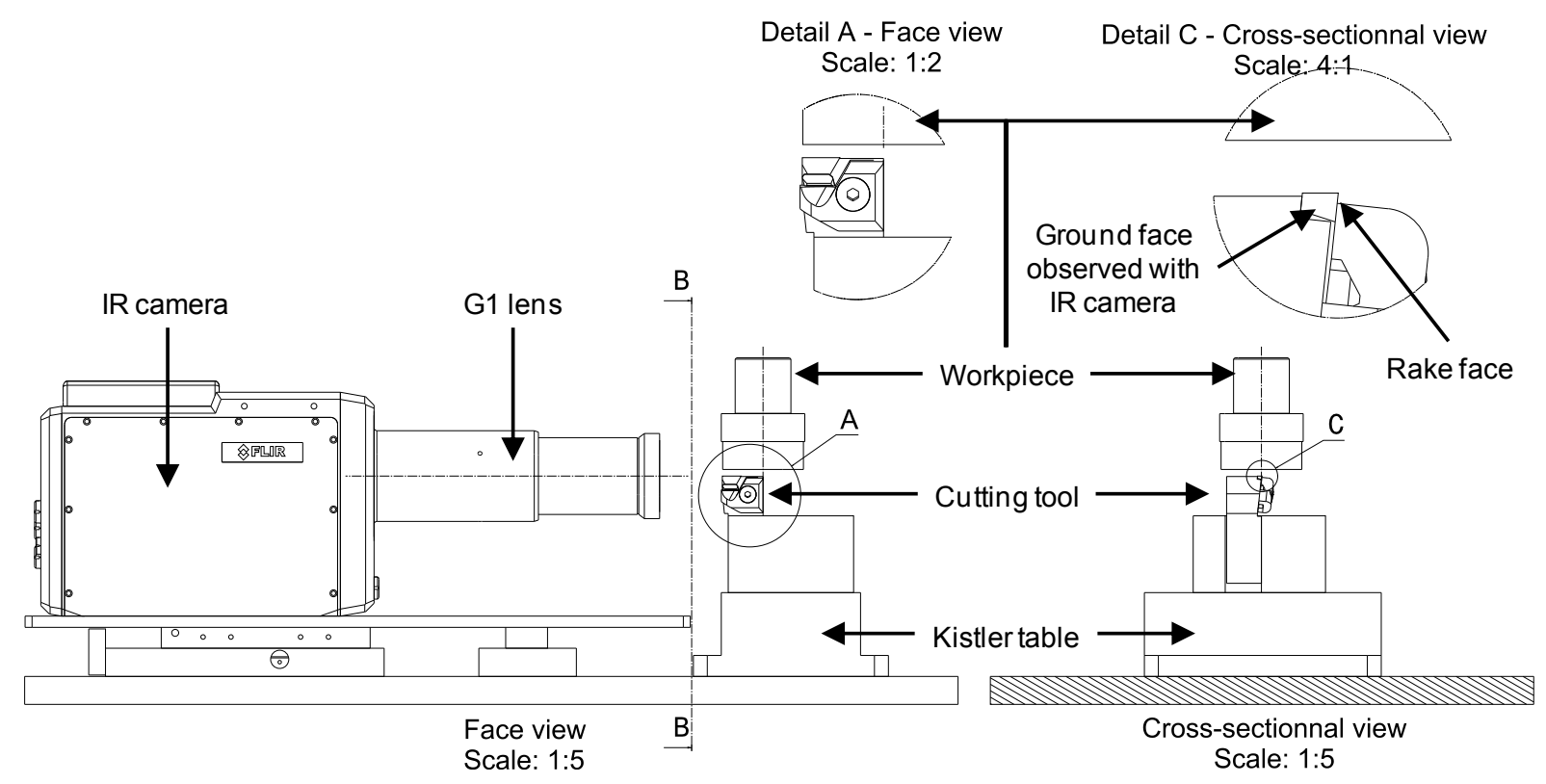

Fig. 2. Thermographic setup used, from (Artozoul et al., 2014).

\section{Results and discussion}

This study focused on Built-Up-Layer formation and its influence on parameters such as cutting forces and cutting temperatures, which are here supposed to characterize machinability. With this objective, the results in terms of cutting forces of bar turning tests (semi-orthogonal cutting tests) and of orthogonal cutting tests are first presented, compared and discussed. SEM observations and EDX analysis are then detailed. By examining the BUL at various cutting lengths, BUL changes with time are also evaluated for different cutting speed values. Additional results about IR temperature measurements are finally examined. To conclude this part, a general discussion about all the results is proposed at the end of this section.

\subsection{Cutting forces}

Cutting forces measured during the bar turning tests are first examined. Fig. 3 shows the evolution of the cutting force and feed force with the Uncut Chip Length during several tests carried out with the same cutting speed value $\left(V_{C}=100 \mathrm{~m} / \mathrm{min}\right)$ but with increasing maximum Uncut Chip Lengths (from 1 to $60 \mathrm{~m}$ ). Generally, the cutting forces are expected to rise slightly with increasing Uncut Chip Length, due to progressive tool wear. Fig. 3 reveals that the cutting forces remain sensibly constant throughout the duration of the cutting tests. In consequence, it can be assumed that the wear is negligible; this was verified by the observation of inserts after machining. For the same reason, the graphs are limited to 3 meters along the $\mathrm{x}$-axis (Uncut Chip Length). In addition, the measured values of $F_{C}$ and $F_{F}$ are the same for all the tests, showing a very good reproducibility of the cutting experiments and measurements.

Peaks in cutting force signals are detected at the beginning of the cutting process, for a cutting length of about $0.3 \mathrm{~m}$. Such cutting force peaks have already been observed when machining improved machinability steels (Grolleau, 1996). They were assumed to be due to BUL formation. Reducing in cutting force is approximately $15 \%$, while it is of about $5 \%$ for feed force. 

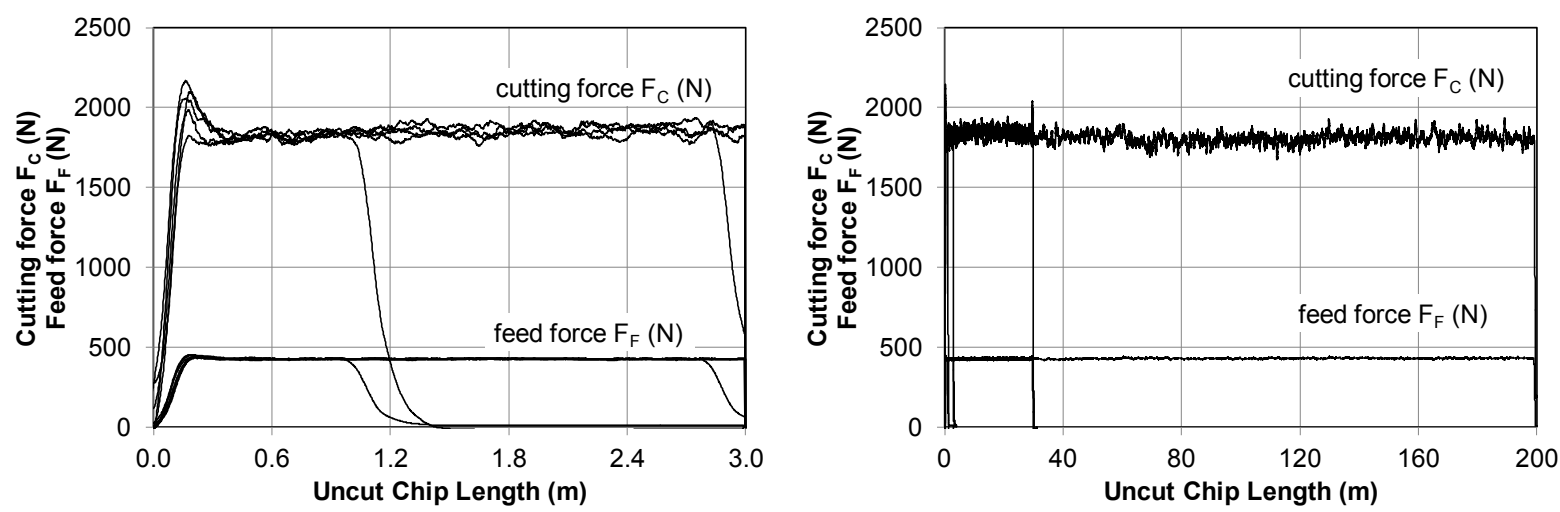

Fig. 3. Cutting and feed forces during turning operations at $V_{C}=100 \mathrm{~m} / \mathrm{min}$ at the tool entry (for UCL less than $3 \mathrm{~m}$ ) and for the whole cutting tests.

Specific cutting and feed forces are evaluated using the following equations:

$k_{C}=\frac{\overline{F_{C}}}{A_{D}} ; \quad k_{F}=\frac{\overline{F_{F}}}{A_{D}}$ with $A_{D}=$ chip area $=f \times a_{p}$

where $\overline{F_{C}}$ and $\overline{F_{F}}$ are respectively the mean cutting force and the mean feed force. Values of $\overline{F_{C}}$ and $\bar{F}_{\mathrm{F}}$ are computed for a significant Uncut Chip Length. Tool wear is regarded as negligible. Two values of friction coefficient at the tool-chip interface are estimated with the relations:

$\mu=\frac{\mathrm{F}_{\mathrm{F}}+\mathrm{F}_{\mathrm{C}} \tan \gamma}{\mathrm{F}_{\mathrm{F}}-\mathrm{F}_{\mathrm{C}} \tan \gamma}$ and $\bar{\mu}=\frac{\overline{\mathrm{F}_{\mathrm{F}}}+\overline{\mathrm{F}_{\mathrm{C}}} \tan \gamma}{\overline{\mathrm{F}_{\mathrm{F}}}-\overline{\mathrm{F}_{\mathrm{C}}} \tan \gamma}$

$\bar{\mu}$ should be regarded as an apparent average friction coefficient since $\mu$ provides an instantaneous value of apparent friction coefficient. The two coefficients take into account both the sticking and the sliding which occurs in the flow zone.

A direct comparison of the values obtained for specific forces and apparent friction coefficient after bar turning tests (semi-orthogonal cutting tests) and after orthogonal cutting tests was realised for all the cutting conditions. It appears that the results are very close for the two cutting operations; using both bar turning tests and orthogonal cutting tests for the experimental procedure is justified.

Fig. 4 shows, for different values of cutting speed, the evolution of the instantaneous apparent friction coefficient just after tool entry. It appears that the friction coefficient reaches very quickly a maximum value at the beginning of the cutting process and then decreases to stabilize at a value which remains constant. This evolution is similar to the one observed for the cutting and feed forces, Fig. 3. Contact conditions at the tool-chip interface change rapidly. Mean values of apparent friction coefficient are rather low (between 0.3 and 0.4 ) and can be attributed to the steel high sulphur content as well as tool coating. 


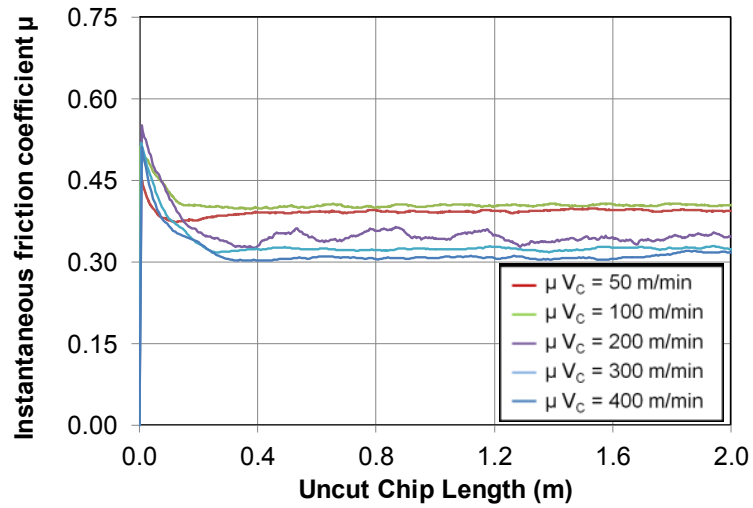

Fig. 4. Evolution of apparent friction coefficient $\mu$ with Uncut Chip Length

Fig. 5 gives the evolution of specific forces and apparent friction coefficient; values are post-processed based on cutting experiments performed in bar turning or orthogonal cutting. Reproducibility is verified for all the cutting conditions tested. Common trends are observed: an increase in cutting speed results in a reduction of both the specific forces and the average friction coefficient.
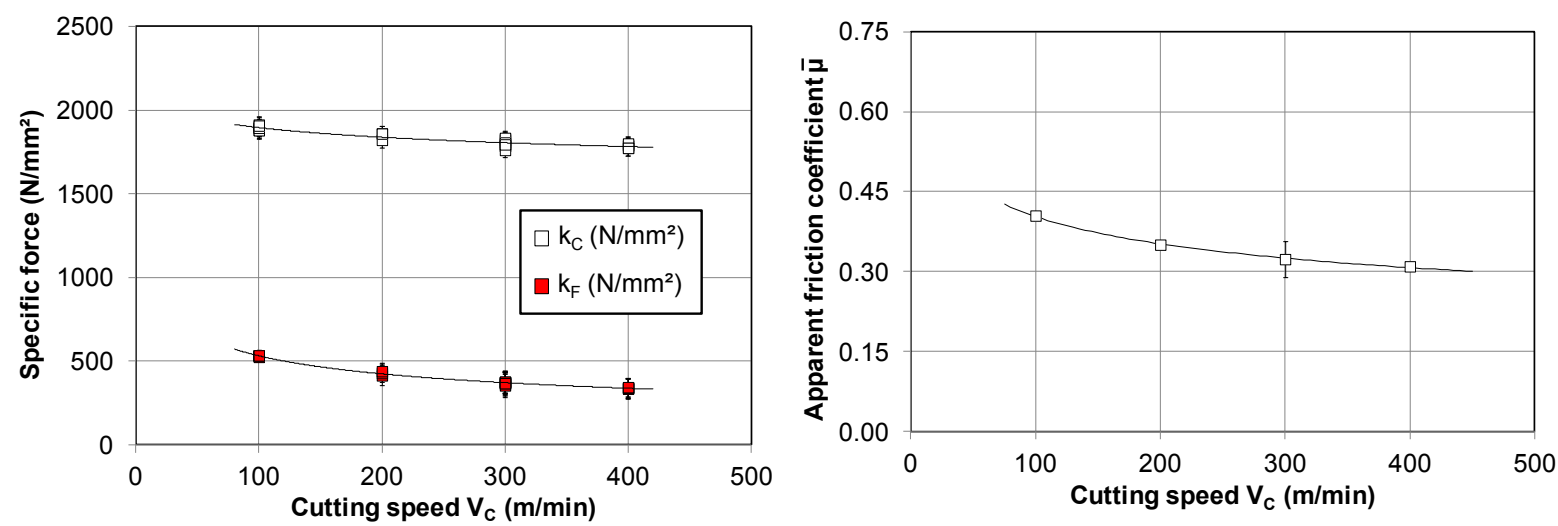

Fig. 5. Variation of specific forces and friction coefficient with cutting speed.

\subsection{Tool rake face micro topography}

After the bar turning experiments, rake face micro topography of all the 20 different cutting inserts were measured using an ALICONA InfiniteFocus SL equipped with a 20x objective. Measurement field was a $1 \times 1 \mathrm{~mm}^{2}$ square. The investigated zone on the rake face is described Fig. 6 . It is located far enough from the tool nose. 


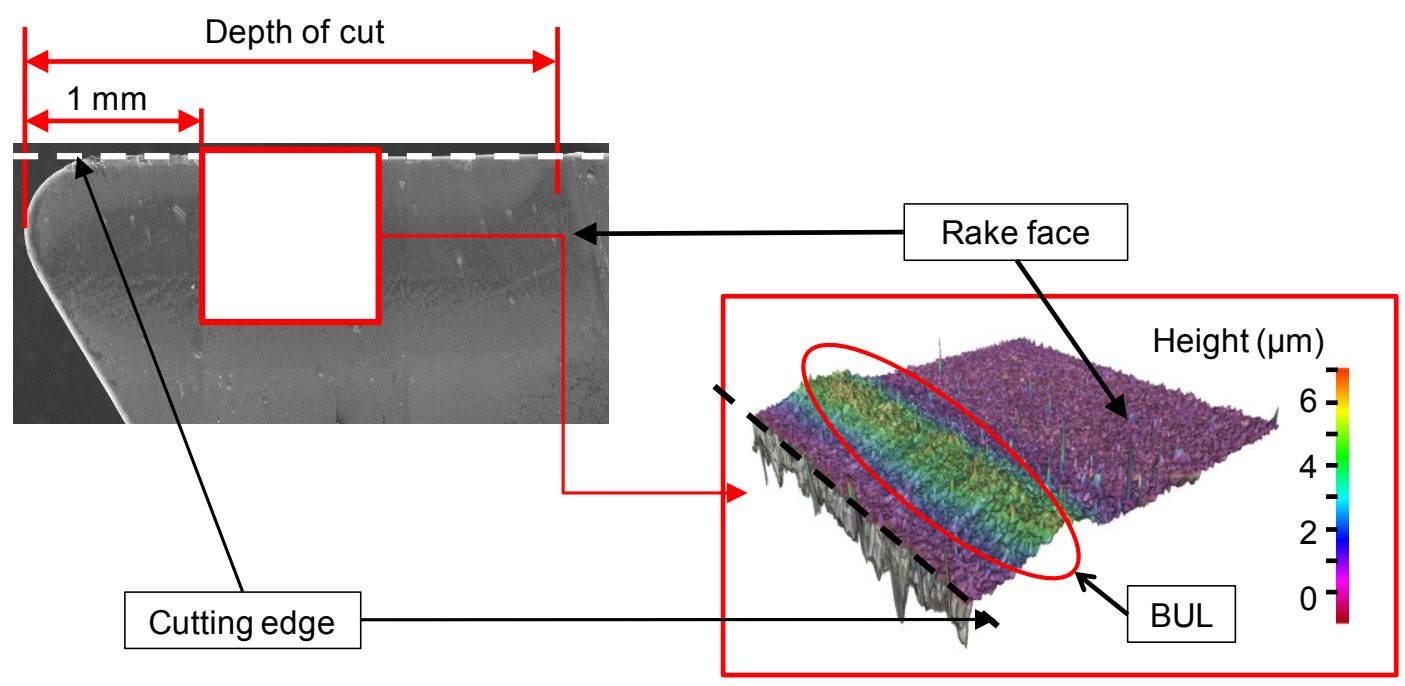

Fig. 6. Chosen area for the topography measurement.

Fig. 7 presents a 3D typical view of a tool rake face topography after machining. The relief resulting from the generated BUL located in the tool-chip contact zone is clearly visible. A mean BUL profile is computed, it represents the BUL morphology for a $1 \mathrm{~mm}$ wide cutting edge located at the middle of the active cutting edge. The negative altitudes at the vicinity of the $\mathrm{X}$-axis origin are due to the cutting edge radius which is about $20 \mu \mathrm{m}$.

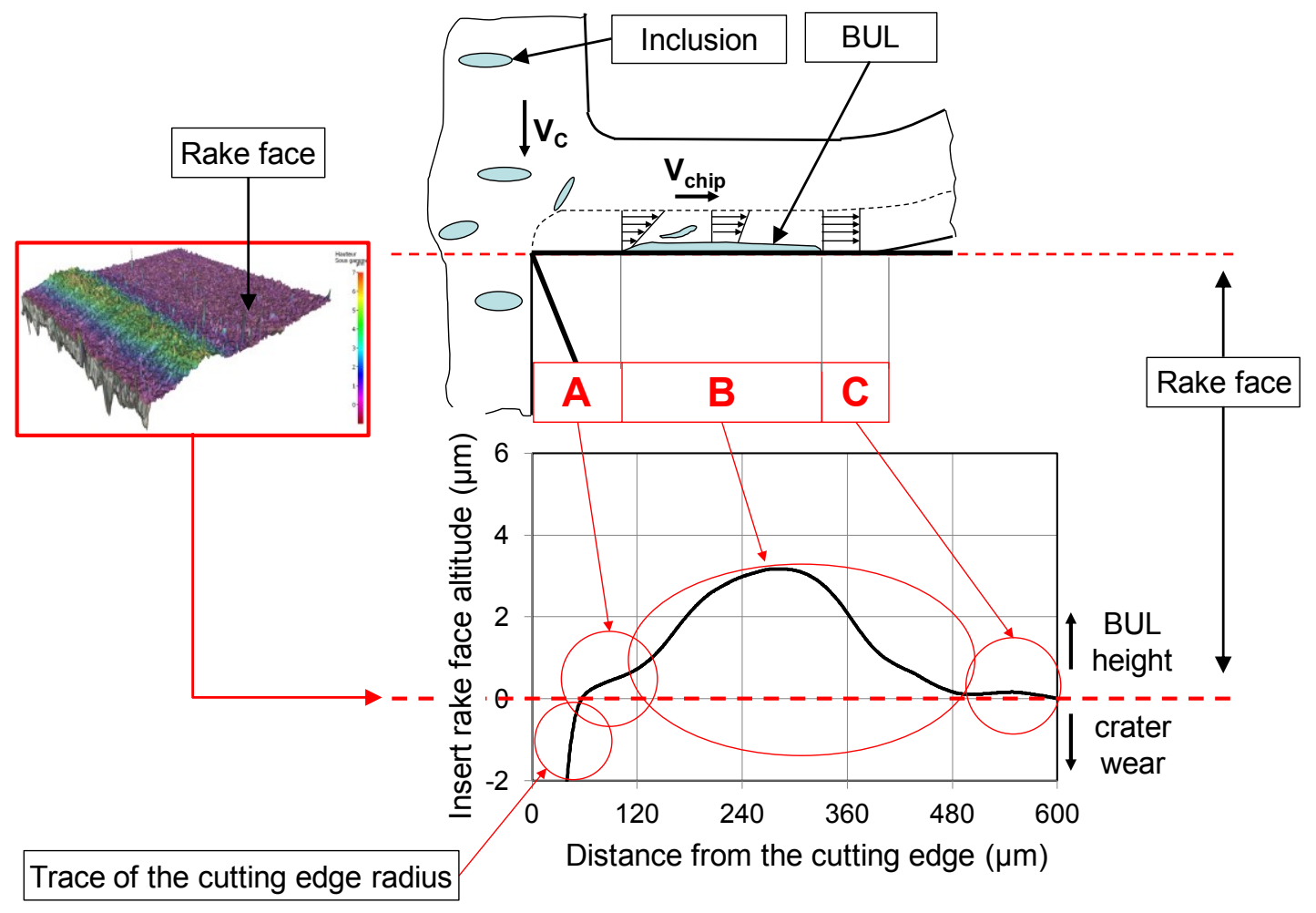

Fig. 7. Typical 3D view of the rake face showing deposit layers and typical BUL mean profile. In accordance with the study of (Larsson and Ruppi, 2001) and (Schultheiss et al., 2013), three different zones may be distinguished in the tool-chip contact area (Fig. 7): 
- A first zone (A), very close to the cutting edge, where a sticking contact exists between chip and cutting tool surfaces with an important velocity gradient within the chip thickness. Very little deposited work material is observed in this zone;

- A second zone (B), mixed shearing and sliding zone, where the chip velocity at the tool-chip interface increases progressively. This zone is covered by work material elements.

- A third zone $(C)$ or sliding zone where the chip moves as a solid body. The quantity of transferred work material is lower than in zone (B).

The BUL is thus formed in the area B, where a high compressive stress is still present (Molinari et al., 2012).

BUL grows progressively and its morphology can change depending on Uncut Chip Length. Fig. 8 presents the evolution of mean BUL profile with Uncut Chip Length for a cutting speed of $200 \mathrm{~m} / \mathrm{min}$. The results point out the promptness of the BUL appearance: a very short UCL $(1 \mathrm{~m})$ is already sufficient to form transfer layers on the rake face. For the shortest lengths ( $1 \mathrm{~m}$ and $3 \mathrm{~m}$ ), the first 150$200 \mu \mathrm{m}$ of the rake face are not fully covered with BUL. BUL maximum thickness position is located at about $300 \mu \mathrm{m}$ from the cutting edge for these UCL. When Uncut Chip Length is greater than $10 \mathrm{~m}$, BUL covers the entire tool-chip contact zone and BUL mean profiles are very similar. These observations let us think that BUL must reach a stabilized morphology after about $10 \mathrm{~m}$ of Uncut Chip Length. All the cutting inserts having machined a short UCL (1, 3, 10 and $30 \mathrm{~m}$ ) have made only one longitudinal turning pass. Results are different for the cutting inserts having machined a longer UCL of $200 \mathrm{~m}$. To reach such longer UCL, it has been necessary to process successive longitudinal turning passes, i.e. successive tool entries and exits from the work piece. These successive entries and exits induce thermo-mechanical loading and unloading cycles at the tool-chip interface and then deeply change the BUL morphology. As a consequence, the former BUL located on the rake of the cutting insert can be partially removed by the sliding chip, and only a small BUL is observed after $200 \mathrm{~m}$. In addition a slight start of tool wear on the rake face can be observed. However this tool wear does not exceed $2 \mu \mathrm{m}$.

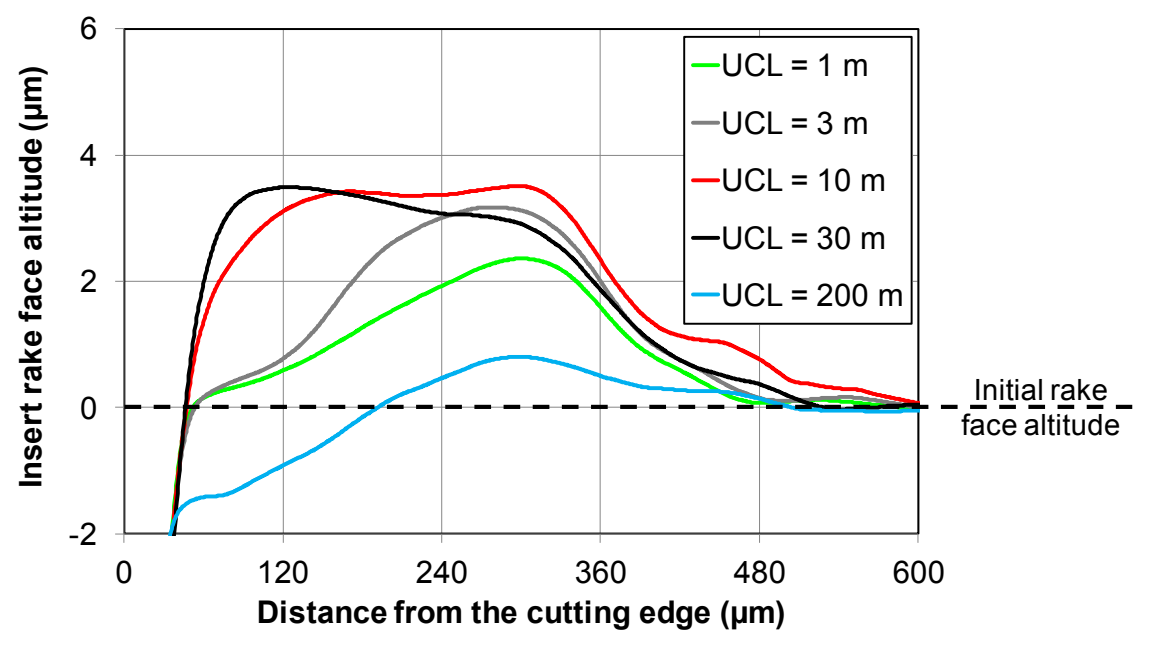

Fig. 8. Evolution of the mean BUL thickness on the rake face of the cutting tool depending on the Uncut Chip Length at $V_{C}=200 \mathrm{~m} / \mathrm{min}$. 
The same observations are also made for the other cutting speeds (except for $100 \mathrm{~m} / \mathrm{min}$ ). Fig. 9 presents the evolution of the average BUL thickness as a function of the speed and of the machined length. The mean BUL thicknesses were calculated using the measured tool-chip contact length.

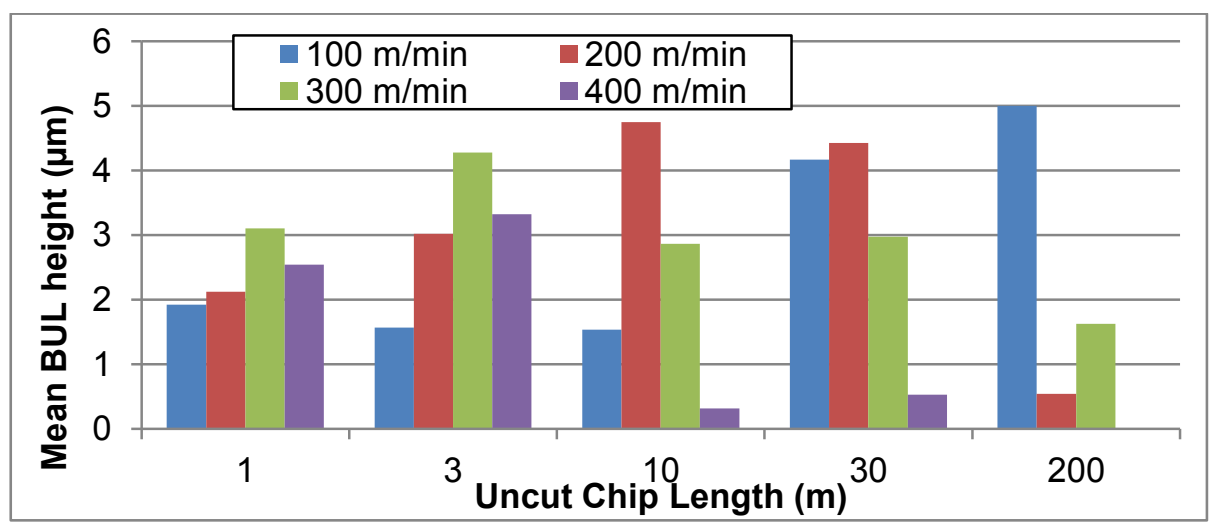

Fig. 9. Evolution of the BUL height

depending on the cutting speed and Uncut Chip Length.

BUL appears rapidly at the lowest cutting speed $\left(V_{C}=100 \mathrm{~m} / \mathrm{min}\right)$. Its thickness is almost constant up to a UCL about $10 \mathrm{~m}$. It is also lower than values measured for higher cutting speeds. It then grows to reach the maximum value of $5 \mu \mathrm{m}$. BUL evolution is very similar for $200 \mathrm{~m} / \mathrm{min}$ and $300 \mathrm{~m} / \mathrm{min}$ cutting speeds. The stabilized BUL thickness appears to be lower for the $300 \mathrm{~m} / \mathrm{min}$ and equal to about $3 \mu \mathrm{m}$. The topographic measurements of the cutting inserts having machined at $V_{C}=400 \mathrm{~m} / \mathrm{min}$ on very short cutting lengths $(1 \mathrm{~m}$ and $3 \mathrm{~m}$ ) show the presence of relative thick layers on the rake face of the cutting tool. However, these thick layers seem to disappear with increasing the cutting length $(10 \mathrm{~m}$, $30 \mathrm{~m}$ and $200 \mathrm{~m}$ ), the highest cutting speed $V_{C}=400 \mathrm{~m} / \mathrm{min}$ does not allow the existence of a BUL on the rake face of the cutting tool. Moreover, a fine observation of the cutting inserts having machined at $V_{C}=400 \mathrm{~m} / \mathrm{min}$ shows that the first signs of wear on the cutting edge appear after an Uncut Chip Length of just $30 \mathrm{~m}$.

These observations allow us to rank the four investigated cutting speeds and Uncut Chip Lengths concerning their ability to ease BUL appearance on the rake face of the tool (see Fig.10).

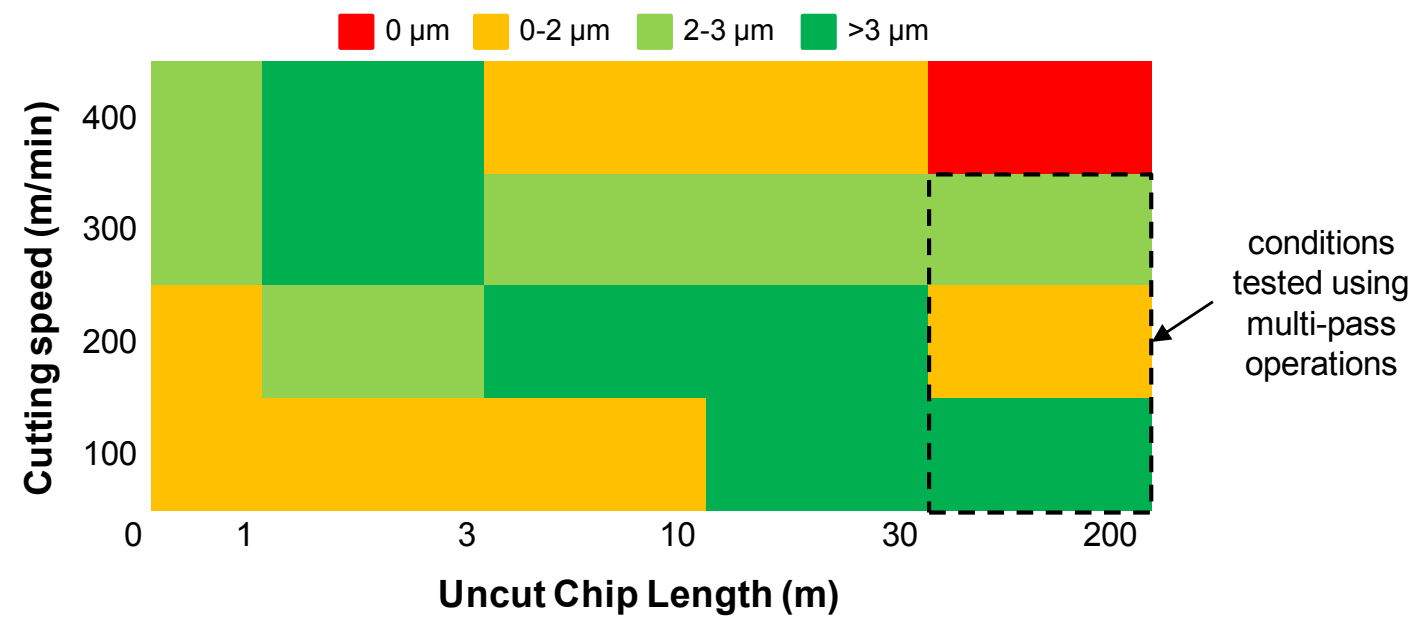

Fig.10. BUL range of existence in $\left(V_{c}, U C L\right)$ 
The light green area represents the domain where the mean BUL height is over $2 \mu \mathrm{m}$ and the green area where the mean BUL height is over $3 \mu \mathrm{m}$. By comparison, the tool coating height of the insert is 2 $\mu \mathrm{m}$. It may be supposed that such a thick BUL is able to protect efficiently the cutting tool from various wear mechanisms, such as abrasive wear or diffusion wear. The larger Uncut Chip Thickness was tested during multi-pass machining operations; thereby, results relating to the BUL thickness should be discussed more carefully. The BUL appears discontinuous and the lacks of deposited work material lead to a decrease of the mean BUL height; however, the BUL may have been damaged during the multiple tool entries and exits. A dotted border is thus used on Fig.10 to highlight these specific cutting conditions.

\section{3. $S E M+E D X$ analysis}

Fig.11 shows an SEM image of the investigated zone and an example of EDX map produced for one of the chemical elements scanned (here sulphur). Differences in BUL covering are significant: BUL density seems higher in the shearing and sliding zone (zone B of the tool chip interface, see Fig. 8). SEM observations and EDX analyses show that melted steel particles are often spread beyond the tool-chip contact zone when machining; however these deposits must not be considered as BULs. The right image shows BUL with a 1200x magnification. Chip Flow Direction is clearly visible and is not strictly perpendicular to the cutting edge. This is due to the action of the tool nose. Cracks are also visible. They are due to tool cooling when the last chip leaves the rake face. For multi-pass machining operations, these cracks may weaken the BUL and then parts of the BUL may be taken away by the chip. In addition to the EDX maps (Fig.11), EDX profiles have been generated.
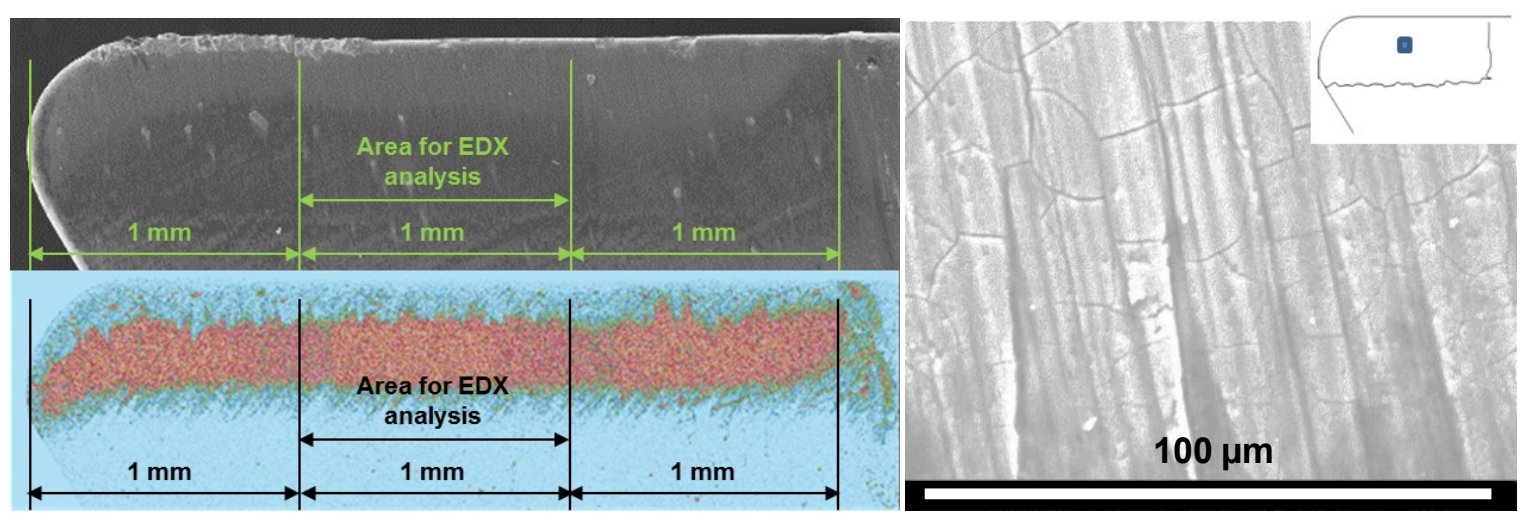

Fig.11. Example of SEM and EDX map for sulphur showing the investigated zone on the rake face of the cutting tool for the EDX analysis $-V_{C}=200 \mathrm{~m} / \mathrm{min}-U C L=3 \mathrm{~m}$.

The results of the SEM + EDX analysis show that the BUL is mainly composed of $S$ and Mn, coming from the transfer of MnS inclusions on the rake face of the cutting tool. Very few traces of oxide inclusions have been found in the tool-chip contact zone. These results suggest that the BULs are mainly the result of the deposition of MnS inclusions on the cutting tool. In addition, SEM + EDS 
analysis confirm results of micro topography: BULs can appear for very short machined lengths (1 m for example) (see Fig.12).
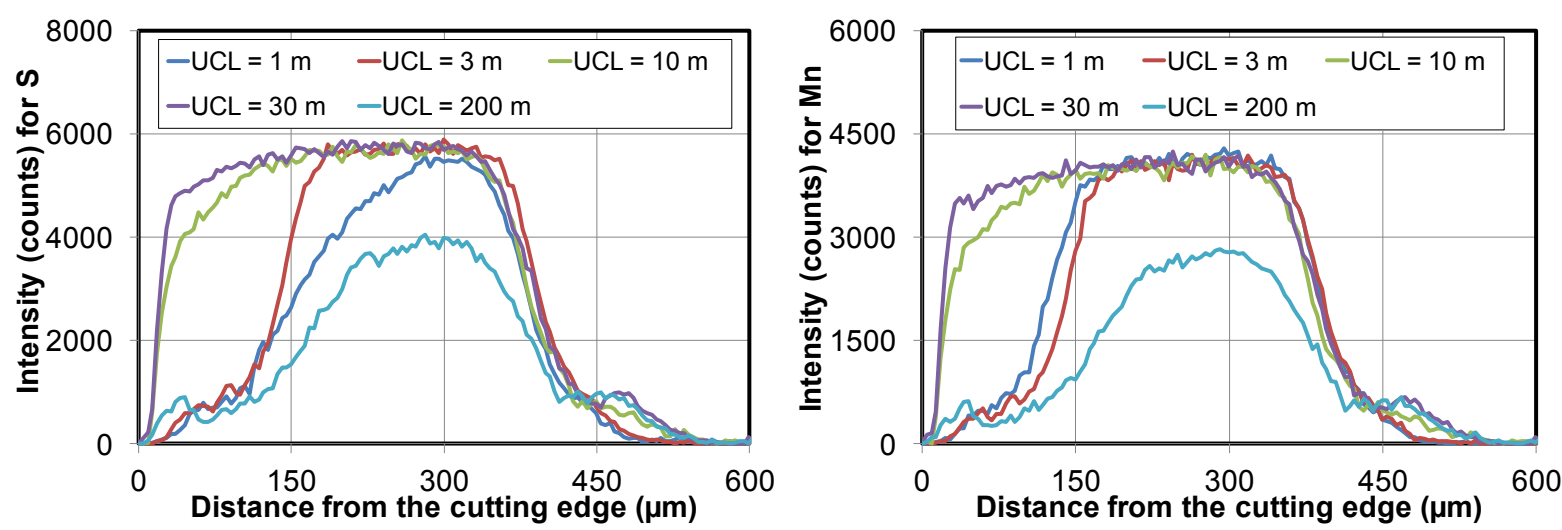

Fig.12. Comparison of EDX profiles of $S$ (left) and $M n$ (right) on the rake face at $V_{C}=200 \mathrm{~m} / \mathrm{min}$, depending on the Uncut Chip Length.

These results are directly linked with the high sulphur content of the machined steel $(0.299 \%)$ and the ability of the tool coating to promote the BUL adhesion. Many authors have already studied the ability of several tool coatings to promote the formation of BUL during machining (Brion, 1993) (Katayama and Imai, 1990) and pointed out the important role that titanium seems to play through its good affinity with sulphur. These results leads us to believe that the coating (AITiSiN) of the used cutting inserts enhances the formation of MnS layers.

The EDX analysis of $\mathrm{Ti}, \mathrm{Si}$ and $\mathrm{Al}$ (which are present in the tool coating) show that the formed BULs are thick enough to hide the tool coating (for an accelerating voltage of $15 \mathrm{kV}$ ).

Several techniques have been tested to measure properly the tool-chip contact length: SEM and optical observations, EDX analysis and IR thermography. Results have been compared; however the best accuracy is reached with EDX analysis. Thermal images post-processing clearly highlights that tool-chip contact length shows small variations. Contact appears as intermittent at the end of the toolchip contact zone. EDX analysis enables to estimate contact severity and then to develop postprocessing techniques avoiding subjectivity. Fig.12 shows that the zone covered by the BUL was about $600 \mu \mathrm{m}$ length for all the investigated cutting conditions. However, it appears that this value is certainly longer than the actual tool-chip contact length. Indeed, at the end of the tool-chip contact zone, some transferred material (i.e. manganese sulphides) can be spread from the chip onto the rake face, and finally hide the actual end of tool-chip contact zone. A fine observation of the tool-chip contact zone leads us to think that the actual tool-chip contact length is about $550 \mu \mathrm{m}$ for the four investigated cutting speeds.

Finally, several remarks can be done:

- BUL, which is due to MnS deposition, have approximately the same length on the tool rake face: about $550 \mu \mathrm{m}$ from the cutting edge (see Fig.12).

- The covered area by the BUL seems stabilized for UCL between $10 \mathrm{~m}$ and $30 \mathrm{~m}$. 
- BUL formation seems to begin first at about $300 \mu \mathrm{m}$ from the cutting edge, and then grows progressively.

All these outcomes are consistent with those provided by micro topography analysis.

\subsection{IR Thermography}

Fig. 13 shows an example of IR image collected with the camera. It clearly shows the faces of the cutting tool as well as the surfaces of the workpiece (the rough one on the left and the machined one on the right). The shear angle $\phi$ may be measured from temperature rise. The tool-chip interface can be easily identified and the temperature distribution computed based on calibration curves.

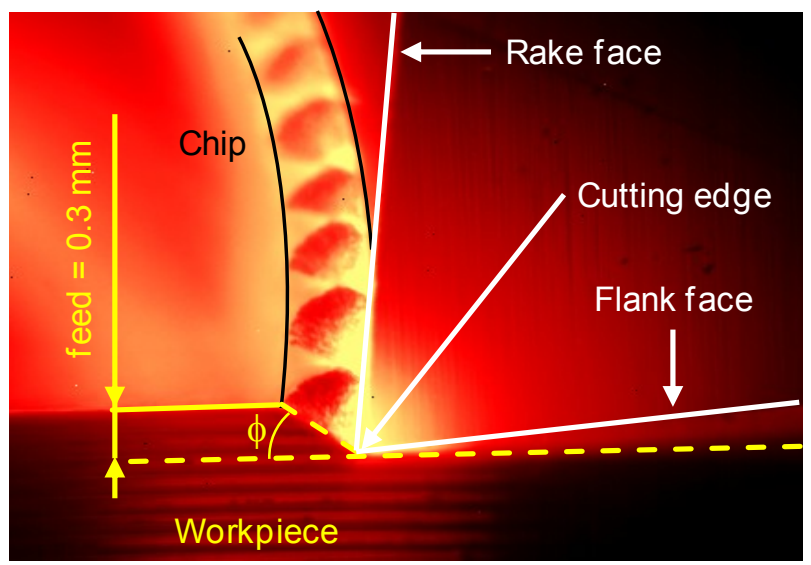

Fig. 13. IR image collected with the camera;

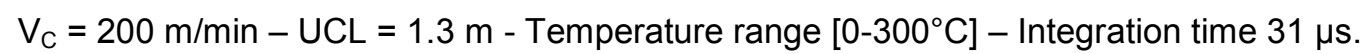

Fig.14 shows the evolution of the temperature distribution at the tool-chip interface during the first 500 ms of the cutting operation (i.e. during the 1.67 first meters of Uncut Chip Length). It appears that the temperature distribution is rapidly modified. A thermal quasi-steady state is reached after $500 \mathrm{~ms}$ (i.e. after just about $1.5 \mathrm{~m}$ of Uncut Chip Length). Temperature curves finally seem to overlap. The maximal temperature is located about $100 \mu \mathrm{m}$ from the cutting edge. In consistency with previous observations, the BUL is formed in an area located after the peak temperature (between 120 and 360 micrometers from the cutting edge). With this increase in temperature, sulphides are more malleable and transfer of these inclusions on the tool rake face is eased. 


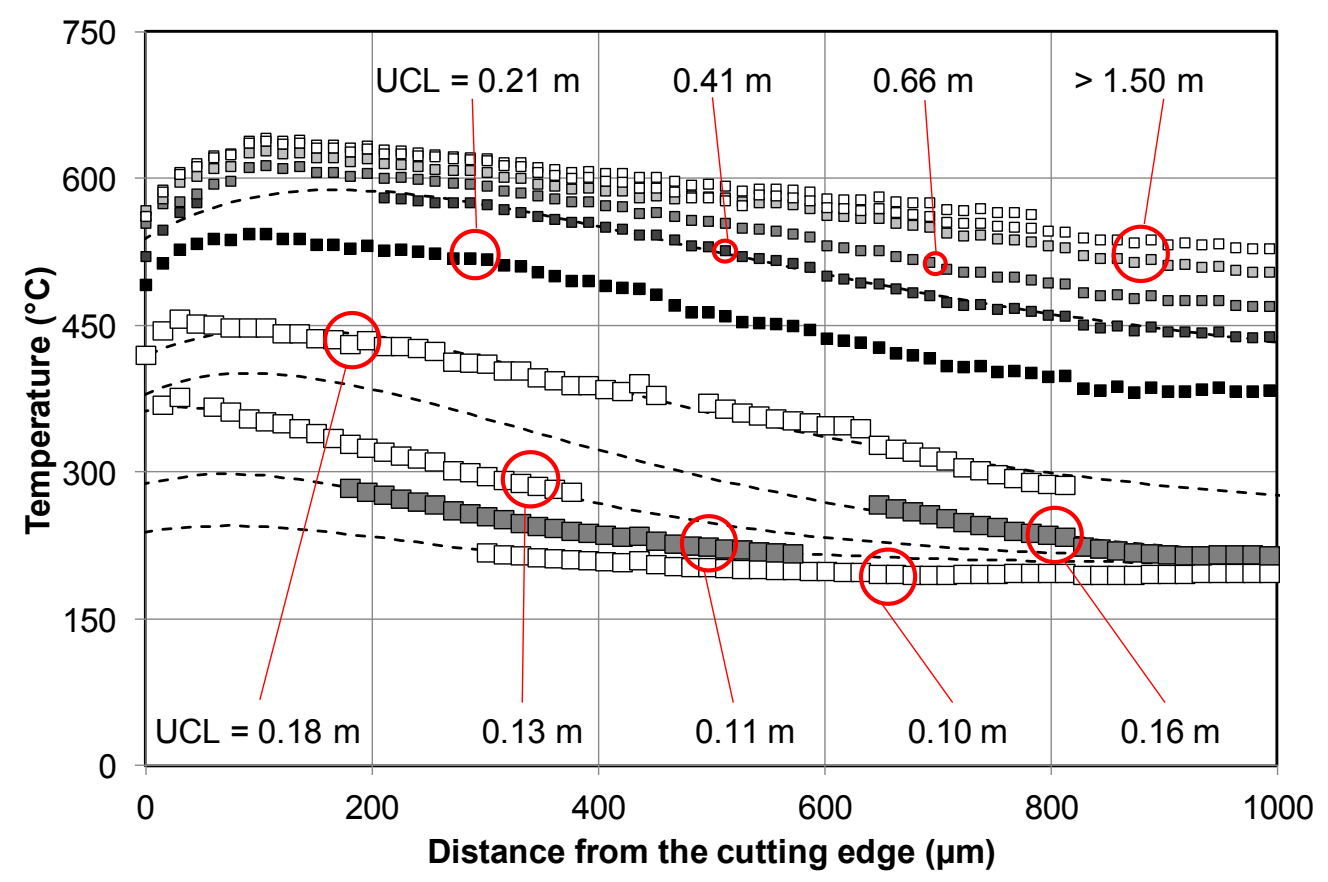

Fig.14. Temperature distribution at the tool rake face during the first $500 \mathrm{~ms}$ of the cutting test.

$$
V_{C}=200 \mathrm{~m} / \mathrm{min}-\mathrm{f}=0.3 \mathrm{~mm} / \mathrm{rev}-\mathrm{ap}=2 \mathrm{~mm} \text {. }
$$

Mean temperature at the tool-chip interface can be considered as the so-called cutting temperature provided by tool-workpiece thermocouple. This temperature was computed for each cutting experiment (see Fig.15). Cutting temperature increases rapidly at the beginning of the cutting operation. After this intense temperature increase, a stabilization of the cutting tool temperature is noticed.
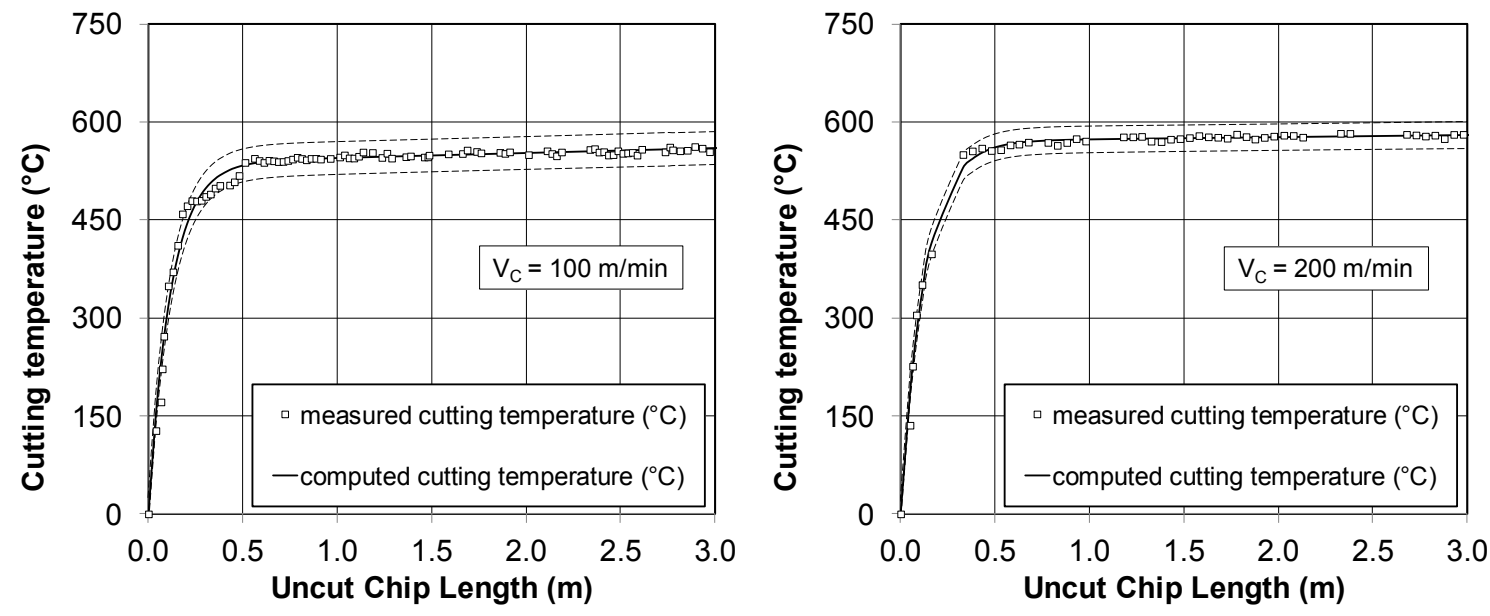

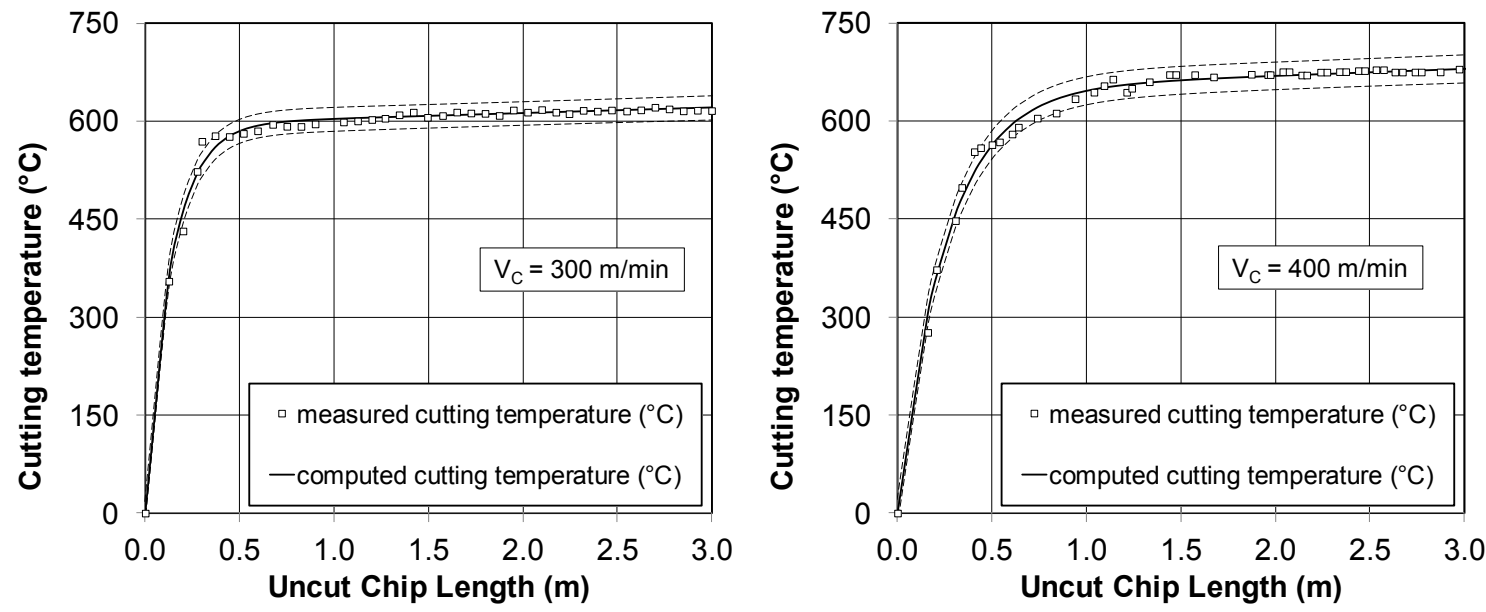

Fig.15. Mean cutting temperature evolution of the of the rake face.

The measured mean cutting temperature was approximated using an empirical model. The model constants are used to compare the thermal evolution of the tool interface for different cutting conditions and to correlate temperature and friction coefficient. The model combines an exponential function for the rapid temperature increase when the tool begins machining and a linear function for the pseudo-stationary state (Artozoul et al., 2014):

$\left.\mathrm{T}=\mathrm{T}_{0}\left(1-\exp \left(\frac{-\mathrm{x}}{\mathrm{L}_{0}}\right)\right)(1+\mathrm{Bx})\right)$

Where $x$ represents the Uncut Chip Length and $T_{0}, L_{0}$ and $B$ are constants. These constants were determined for each cutting test using a least square method: the coefficient of determination $R^{2}$ is also proposed to check the relevancy of the chosen model. The constant $T_{0}$, may be considered as a temperature. The constant B characterizes the linear evolution of the temperature in the pseudosteady state; when $B$ is found small enough, the stationary assumption may be easily accepted. The constant $L_{0}$ is equivalent to a response time but is expressed as a length. It should be regarded as proportional to the Uncut Chip Length necessary to overcome the transient state due to the tool entry. Table 5 gives values of these constants for each tested cutting speed.

\section{Table 5}

Parameters for the temperature evolution versus Uncut Chip Length.

\begin{tabular}{ccccc}
\hline $\mathrm{V}_{\mathrm{C}}(\mathrm{m} / \mathrm{min})$ & $\mathrm{T}_{0}\left({ }^{\circ} \mathrm{C}\right)$ & $\mathrm{L}_{0}(\mathrm{~m})$ & $\mathrm{B}\left({ }^{\circ} \mathrm{C} / \mathrm{m}\right)$ & $\mathrm{R}^{2}$ \\
\hline 100 & 537 & 0.118 & $1.4 \mathrm{E}-2$ & 0.9994 \\
200 & 571 & 0.126 & $6.0 \mathrm{E}-3$ & 0.9997 \\
300 & 595 & 0.135 & $1.4 \mathrm{E}-2$ & 0.9998 \\
400 & 648 & 0.253 & $1.6 \mathrm{E}-2$ & 0.9997 \\
\hline
\end{tabular}

An increase in cutting speed induces an increase in $T_{0}$. As a consequence the mean temperature at the tool-chip interface increases with the cutting speed, which is in accordance with other results from 
the literature. The values of $L_{0}$ increases with the increasing cutting speed. The pseudo-steady state mean cutting temperature is achieved for an Uncut Chip Length of 3 times $L_{0}$.

The mean pseudo-steady temperature of the cutting tool (taken after an Uncut Chip Length of $3 \mathrm{~m}$ ) and the specific cutting force depending on the investigated cutting speed are plotted on Fig.16. Only a slight decrease of the specific cutting force is observed while mean temperature increases from $543^{\circ} \mathrm{C}$ for $V_{C}=100 \mathrm{~m} / \mathrm{min}$ to $656^{\circ} \mathrm{C}$ for $V_{C}=400 \mathrm{~m} / \mathrm{min}$ (see Fig. 16 ).

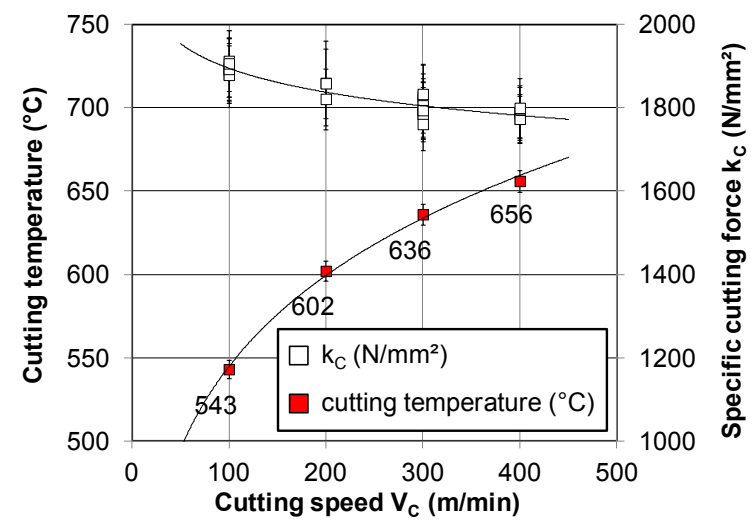

Fig.16. Mean rake temperature and specific cutting force evolution with cutting speed.

Fig.17 shows the four pseudo-steady state temperature distributions, depending on the chosen cutting speeds. The four temperature distributions have the same trend regarding the position of maximum temperature located at about $100 \mu \mathrm{m}$ from the cutting edge. As previously observed (see Fig.16), the increase in temperature with the increasing cutting speed is not linear, and relatively low.

In the case of engineering steels, M'Saoubi and Chandrasekaran (2004) have pointed out that an increase in cutting speed can result in a displacement of the maximum tool temperature point closer towards the cutting edge. The temperature distributions measured show that the increase in cutting speed does not result in such a phenomenon. 


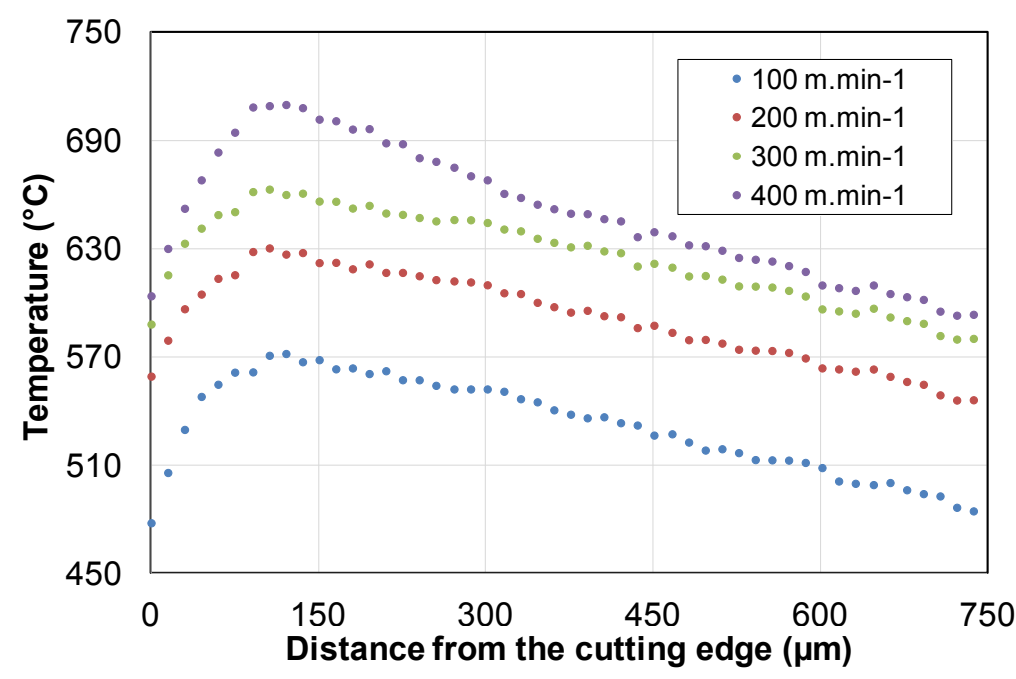

Fig.17. Steady-state temperature distributions on the rake face depending on the cutting speed.

For all the cutting conditions investigated, temperature distributions show two main zones:

- From 0 to $100 \mu \mathrm{m}$ from the cutting edge: the temperature increases rapidly due to the plastic shear occurring in this zone which corresponds to sticking zone defined previously.

- Beyond $100 \mu \mathrm{m}$ from the cutting edge: the temperature decreases almost linearly. In this zone, sliding contact appears progressively and the shear decreases gradually up to the end of the tool chip contact length (almost $550 \mu \mathrm{m}$ far from the cutting edge). Beyond the tool-chip contact zone, temperature still decreases linearly.

\subsection{Discussion}

At the very beginning of the cutting operation (the first decimeters of Uncut Chip Length), the cutting forces increase and reach a peak and then decrease to almost steady values, Fig. 3. This peak was also observed by Hamann et al. (1994) and was linked to BUL formation; however this explanation should be balanced. A peak in cutting forces signal is much more complex to discuss since it is also observed when machining steel without BUL formation. According to our results, it appears rather associated with the transient thermo-mechanical state at the beginning of the cutting process. Indeed, the peak in cutting forces is observed for an UCL between 0.1 and $0.25 \mathrm{~m}$ and, at the same time, the temperature at the tool-chip interface (Fig.15) increases very rapidly and the instantaneous friction coefficient (Fig. 4) decreases significantly. BUL appears quickly, however the EDX analyses (Fig.12) show that the BUL is not stabilized before an UCL between 3 and $10 \mathrm{~m}$.

The role that the cutting temperature plays on the tool-chip friction coefficient has already been investigated. Temperature is commonly supposed to reduce apparent tool-chip friction coefficient: metal cutting modeling based on this assumption proposes relevant trends and theoretical results close to experimental values (Moufki et al., 1998). Tribological experiments dedicated to the tool- 
workpiece tribo-system also show that friction coefficient decreases when sliding speed increases (Zemzemi et al., 2009). The BUL also decreases the cutting force and feed force. This decrease seems to have a higher impact on the feed force. As a result, the tool-chip friction coefficient reaches a low value (about 0.35 ) and the severity of the contact conditions at the tool-chip interface is reduced.

SEM observations and EDX analyses indicated that the BULs were mainly the result of the deposition of MnS inclusions. Such a trend is in accordance with the result of the analyses of the inclusions in the steel. The measurements also show that the main part of the tool-chip contact zone is already covered after an Uncut Chip Length of only $10 \mathrm{~m}$. The high sulphur content of the steel (almost $0.300 \%$ ) as well as the tool coating (AITiSiN) explains this very quick BUL appearance. For longer cutting lengths $(>10 \mathrm{~m})$, the BUL does not grow, it remains stable on the cutting face or is evacuated with the sliding chip and then renewed.

Cutting speed plays a major role on the BUL formation. Firstly, an increase in cutting speed leads to an increase in chip sliding speed and a decrease in friction coefficient. As a consequence, MnS inclusions which were revealed by the cutting edge and which slide on the tool rake face have less time to be transferred (partially or totally) onto the rake face. Nevertheless they adhere and then become part of the BUL. Moreover an increase in cutting speed leads to a higher temperature at the tool-chip interface, which modifies steel and inclusions viscosity as well as BUL mechanical properties.

Tool measurements have shown that BULs are completely formed at an Uncut Chip Length of about 10 meters i.e. much more than the UCL for which the thermal pseudo-steady state is reached (about $1.5 \mathrm{~m}$ ). For longer Uncut Chip Lengths, BUL did not increase in size but its morphology remained stable. However, BUL is certainly evacuated continuously with the sliding chip and renewed continuously due to the newly transferred sulphide inclusions provided by the steel.

Machining tests suggest that there should be a threshold value for cutting temperature above which $\mathrm{BUL}$ is unable to remain stable on the tool rake face. This temperature is about $650^{\circ} \mathrm{C}$ for the steel being machined and the tool being used. This leads us to believe that BUL range of existence should be expressed using both cutting speed and Uncut Chip Length. Brief machining operations could be then performed at high cutting speed allowing BUL to appear: in an industrial context involving a production in series, the UCLs of the turning passes are currently less than $30 \mathrm{~m}$. Inclusions as well as tools and cutting conditions should be selected to protect the cutting tool efficiently with the BUL as far as possible. The promptness to form a BUL appears as the most critical point. These results correspond to those of other authors (Brion, 1993).

All the observed BULs present an important number of cracks (see Fig.11); these cracks may be attributed to thermal stresses occurring during the cooling of the tool during the machining process. Such phenomenon has already been reported for free cutting steels (Brion, 1993) or engineering steels (Nordgren and Melander, 1990). These cracks may amplify the tendency of the BUL to break up and not to remain stable on the cutting tool. This phenomenon may be more prominent when the cutting tool makes several successive longitudinal turning passes involving successive tool entries and exits from the workpiece. High sulphur content in free-cutting steels allows them to generate protective 
BULs extremely quickly. This is why the choice of both tool coating and cutting conditions may play an essential role promoting an efficient BUL appearance and thus protecting the cutting tool.

\section{Conclusions}

The main objective of this work was to analyze the BUL formation during the cutting process of Usimax $®$ D950, a high strength free-cutting steel with $0.3 \%$ sulphur content and specific metallurgical treatments for machinability enhancement. These experiments provided also an opportunity to test a new AISiTiN coating. Cutting tests investigated wide ranges in cutting speed (from 100 to $400 \mathrm{~m} / \mathrm{min}$ ) and Uncut Chip Length (from 1 to $200 \mathrm{~m}$ ) to cover a broad spectrum of industrial applications.

A complete original experimental approach was proposed and performed. Cutting forces and cutting temperatures were measured during semi-orthogonal (bar turning) and orthogonal cutting tests. All the cutting inserts were examined using SEM with EDX analysis and 3D measurements were taken to characterize the formed BUL. The chemical composition of BUL was obtained and the outcome of the BUL over time was studied. Links between BUL formation, temperature distribution and apparent friction coefficient at tool-chip interface were established. Significant BULs were produced with local thicknesses up to $12 \mu \mathrm{m}$ and average thicknesses up to $5 \mu \mathrm{m}$. BULs were mainly composed of MnS inclusions coming from the steel. It appears that the BUL is formed in the sliding and shearing zone of the tool-chip interface.

\section{Acknowledgements}

The authors would like to thank ArcelorMittal and especially Mrs Marie Claire Estivalet-Sionneau and Mr Pascal Buessler for the confidence they have placed in them. The authors would also like to thank the French Ministry of Higher Education and Research for their financial support. The authors are grateful to Mrs Anne Calvez and Dr Raphael Pesci for their technical support and advice. The authors would also like to thank Olivier Pinoli, Louis Schneider, Victor Pontette and Paul Pechambert for their involvement in this study.

\section{References}

Artozoul, J., Lescalier, C., Bomont, O., Dudzinski, D., 2014. Extended infrared thermography applied to orthogonal cutting: Mechanical and thermal aspects. Applied Thermal Engineering, 64(1-2), 441452.

Bernsmann, G., Bleymehl, M., Ehl, R., Hassler, A., 2001. The making of free cutting steels with additions of lead, bismuth, tellurium, selenium and tin. Stahl und Eisen, 121(2), 87-91.

Bittes, G., 1993. Contribution à la connaissance des mécanismes fondamentaux liés à l'usinabilité des aciers de construction mécanique. PHD Thesis: Université de Toulon et du Var, Toulon, France. 
Brandt, G., Mikus, M., 1987. The formation of protective layers when machining steels with ceramic cutting tool. Wear, 118(1), 99-112.

Brion, J. M., 1993. Contribution à l'étude des mécanismes de formation des couches de transfert non métalliques sur un outil en coupe continue d'aciers de décolletage à inclusions contrôlées. PHD Thesis: Institut National Polytechnique de Lorraine, Nancy, France.

Chandrasekaran, H., 1988. Material development and its role in advanced machining situations. Journal of Mechanical Working Technology, 17, 119-136.

Essel, I., 2006. Machinability enhancement of non-leaded free cutting steels. Shaker Verlag, Aachen.

Gladman, T., Pickering, F. B., 1962. A modern approach to ferrous metallography. Steel and Coal, 1178-1187.

Grolleau, V., 1996. Approche de la validation expérimentale des simulations numériques de la coupe avec prise en compte des phénomènes locaux à l'arête de l'outil. PHD Thesis: Ecole Centrale de Nantes, Nantes, France.

Hamann, J., Le Maître, F., Guillot, D., 1994. Selective transfer Built-Up Layer displacement in high speed machining - Consequences on tool wear and cutting forces. CIRP Annals, 43(1), 69-72.

Helistö, P., Helle, A. S., Pietikäinen, J., 1990. Interface phenomena between oxide layers and cemented carbide tools. Wear, 139(2), 225-234

Helle, A. S., 1995. On the interaction between inclusions in steel and the cutting tool during machining. PHD Thesis: Helsinki University of Technology, Helsinki, Finland.

Katayama, S., Hashimura, M., 1993. Effect of tool materials on adhesion between free-machining steel and cutting tool. Journal of the Japan Society for Precision Engineering, 59, 1991-1996.

Katayama, S., Imai, T., 1990. Effect of tool materials on surface machined roughness and cutting force of low-carbon resulfurized free-machining steels. ISIJ International, 30(4), 331-337.

Kiessling, R., Lange, N., 1990. Non-metallic inclusions in steel. Maney Publishing, London.

Kirsch-Racine, A., Bomont-Arzur, A., Confente, M., 2007. Calcium treatment of medium carbon steel grades for machinability enhancement: from the theory to industrial practice. Revue de Métallurgie, 12, 591-597.

Klocke, F., 2001. Machining and machinability. In: Encyclopedia of materials: science and technology, Elsevier, Amsterdam, pp. 4683-4688.

Larsson, A., Ruppi, S., 2001. Structure and composition of built-up layers on coated tools during turning of Ca-treated steel. Materials Science and Engineering A, 313(1-2), 160-169.

Molinari, A., Cheriguene, R., Miguelez, H., 2012. Contact variables and thermal effects at the tool-chip interface in orthogonal cutting. International Journal of Solids and Structures, 49, 3374-2796.

Moufki, A., Molinari, A., Dudzinski, D., 1998. Modelling of orthogonal cutting with a temperature dependant friction law. Journal of the Mechanics and Physics of Solid, 46(10), 2103-2138. 
M'Saoubi, R., Chandrasekaran, H., 2004. Investigation of the effects of tool micro-geometry and coating on tool temperature during orthogonal turning of quenched and tempered steel. International Journal of Machine Tools \& Manufacture, 213-224.

M'Saoubi, R., Chandrasekaran, H., 2005. Innovative methods for the investigation of tool-chip adhesion and layer formation during machining. CIRP Annals, 54(1), 59-62.

Naylor, J., Llewellyn, T., Keane, M., 1976. Control of machinability in medium carbon steels. Metals Technology, 3(1), 254-271.

Nordgren, A., Melander, A., 1990. Tool wear and inclusion behaviour during turning of calcium treated quenched and tempered steel using coated cemented carbide tools. Wear, 139(2), 209-223.

Opitz, H., König, W., 1962. Zerspanbarkeit von Werkstücken aus verschiedenen Schmelzen des Stahles CK45. Archiv für das Eisenhüttenwesen, 33(12), 831-839.

Qi, H. S., Mills, B., 2000. Formation of a transfer layer at the tool-chip interface during machining. Wear, 245(1-2), 136-147.

Ruppi, S., Högrelius, B., Huhtiranta, M., 1998. Wear characteristics of TiC, Ti(C,N), TiN and Al2O3 coatings in the turning of conventional and Ca-treated steels. International Journal of Refractory Metals and Hard Materials, 16(4-6), 353-368.

Schultheiss, F., Fallqvist, M., M'Saoubi, R., Olsonn, M., Stahl, J. E., 2013. Influence of the tool surface micro topography on the tribological characteristics in metal cutting - Part II Theoretical calculations of contact conditions. Wear, 298-299, 23-31.

Sims, C.E., Dahle, F.B., 1398. Effect of aluminium on the properties of medium carbon cast steel. Transactions of the American Foundrymen's Association, 46, 65-132.

Stahl, J., 2012. Metal cutting: theories and models. SecoTools, Fagersta.

Trent, E. M., Wright, P., 2000. Metal cutting. Butterworth Heinemann, Oxford.

Wang, X., Jawahir, I. S., 2007. Recent advances in plasticity applications in metal machining: slip-line models for machining with rounded cutting edge restricted contact grooved tools. International Journal of Machining and Machinability of Materials, 2(3/4), 347-360.

Wicher, A., Pape, R., 1967. Über die Bildung oxydischer Beläge auf Hartmetallwerkzeugen be der Zerspannung von Stahl. Stahl und Eisen, 87(20), 1169-1178.

Zemzemi, F., Rech, J., Bensalem, W., Dogui, A., Kapsa, P., 2009. Identification of a friction model at tool / chip / workpiece interfaces in dry machining of AISI 4142 treated steels. Journal of Materials Processing Technology, 209, 3978-3990. 